\title{
COMPOSIÇÃO FLORÍSTICA E FITOSSOCIOLOGIA DE CAXETAIS DO LITORAL DO ESTADO DO PARANÁ - BRASIL
}

\author{
Franklin Galvão \\ Carlos Vellozo Roderjan ${ }^{2}$ \\ Yoshiko Saito Kuniyoshi ${ }^{3}$ \\ Sílvia Renate Ziller
}

\begin{abstract}
RESUMO
São apresentadas informações florísticas e fitossociológicas de caxetais - comunidades vegetais caracterizadas pela presença de Tabebuia cassinoides (Lam.) DC.- localizados na planície litorânea do estado do Paraná. Além da abordagem descritiva, são focalizados aspectos sucessionais dessas formações, analisados a partir de mudanças na densidade e dominância da espécie nos ambientes considerados.
\end{abstract}

Palavras-chave: Caxetais, Tabebuia cassinoides, fitossociologia, sucessão vegetal

\section{FLORISTIC AND PHYTOSSOCIOLOGICAL COMPOSITION OF “CAXETAIS” IN PARANÁ STATE COAST - SOUTHEASTERN BRAZIL}

\begin{abstract}
Floristic and phytossociological data on Tabebuia cassinoides (Lam.) DC. (caxeta) communities are presented for the Paraná State coast, Southern Brazil. Apart from the descriptive approach, inferences on the successional development of these communities, which are included in the Atlantic ecosystem, are made based on changes in density and dominance of the species.
\end{abstract}

Keywords: Floristic, Tabebuia cassinoides, community ecology, succession

\section{INTRODUÇÃO}

A cobertura vegetal da planície litorânea do estado do Paraná tem uma história relativamente recente. Evidências indicam que, há cerca de 2.500 anos, o nível médio do oceano era de 2 metros acima do atual, o suficiente para cobrir e influenciar grande parte dessa superfície (Angulo, 1992). O recuo progressivo do mar e a forte ação dos ventos e das marés induziram a formação de feições geomórficas diferenciadas, resultando desde tabuleiros arenosos situados em ambientes de altimetria levemente mais elevada e de drenagem rápida, até formas aconcavadas, também arenosas, configurando as bacias de inundação, abastecidas em sua maior parte por águas pluviais, abundantes no período.

Em ambas as situações, as superfícies foram sendo ocupadas por diferentes formas de vida vegetal, dando início ao processo de sucessão natural, que tem nas florestas a expressão máxima de desenvolvimento na região. Especificamente no ambiente das

\footnotetext{
${ }^{1}$ Eng. Florestal, Dr., Departamento de Ciências Florestais da UFPR, Curitiba-PR, fgalvao@ floresta.ufpr.br

${ }^{2}$ Eng. Florestal, Dr., Departamento de Ciências Florestais da UFPR, Curitiba-PR, roderjan@ floresta.ufpr.br

${ }^{3}$ Naturalista, Dr ${ }^{\mathrm{a}}$., Departamento de Ciências Florestais da UFPR, Curitiba-PR, yoshiko@floresta.ufpr.br

${ }^{4}$ Eng. Florestal, Dr ${ }^{\mathrm{a}}$., Instituto Hórus, Curitiba-PR, sziller@sul.com.br

Recebido para publicação: 04/2001

Aceito para publicação: 06/2002
} 
bacias de inundação é que se estabeleceram os caxetais, associações arbóreas com predomínio da caxeta (Tabebuia cassinoides (Lam.) DC.).

A partir de meados do século passado iniciou-se um processo acelerado de transformação da vegetação da planície, decorrente de diferentes formas de ocupação humana como a agricultura, a exploração madeireira (Maack, 1981) e, mais recentemente, a pecuária e a urbanização. Os caxetais foram, em grande parte, poupados neste processo de transformação, devido ao elevado valor comercial da madeira da caxeta e à sua capacidade de regeneração, mediante rebrota das cepas (Kuniyoshi, 1993). Foram também determinantes o elevado nível de saturação hídrica, assim como o reduzido grau de trafegabilidade dos seus solos, restringido a maioria das práticas agrícolas tradicionais (Rachwall e Curcio, 2001).

O que se discute, atualmente, é a viabilidade econômica da manutenção dos caxetais, ante a opção do plantio e utilização de outras espécies arbóreas para os mesmos fins - lápis de alta qualidade, instrumentos musicais, artesanato, entre outros -, a exaustão da sua capacidade regenerativa em função do manejo inadequado e a pressão das atividades imobiliárias e da criação de búfalos. Com este trabalho objetiva-se, portanto, através da reunião de informações sobre a sua composição florística e estrutural em diferentes localidades do litoral do estado do Paraná, contribuir para a compreensão dessas comunidades vegetais e para a perpetuação e o desenvolvimento da atividade de utilização desse recurso natural.

\section{MATERIAL E MÉTODOS}

As informações contidas neste trabalho decorrem de levantamentos feitos pelos autores em sete comunidades arbóreas, reconhecidas pelos práticos e nos meios acadêmicos como caxetais, localizadas na planície litorânea do estado do Paraná (Ziller, 1992; Roderjan et al., 1997), entre latitudes de 25 e $26^{\circ}$ Sul e longitudes de 48 e $49^{\circ}$ Oeste (Figura 1).
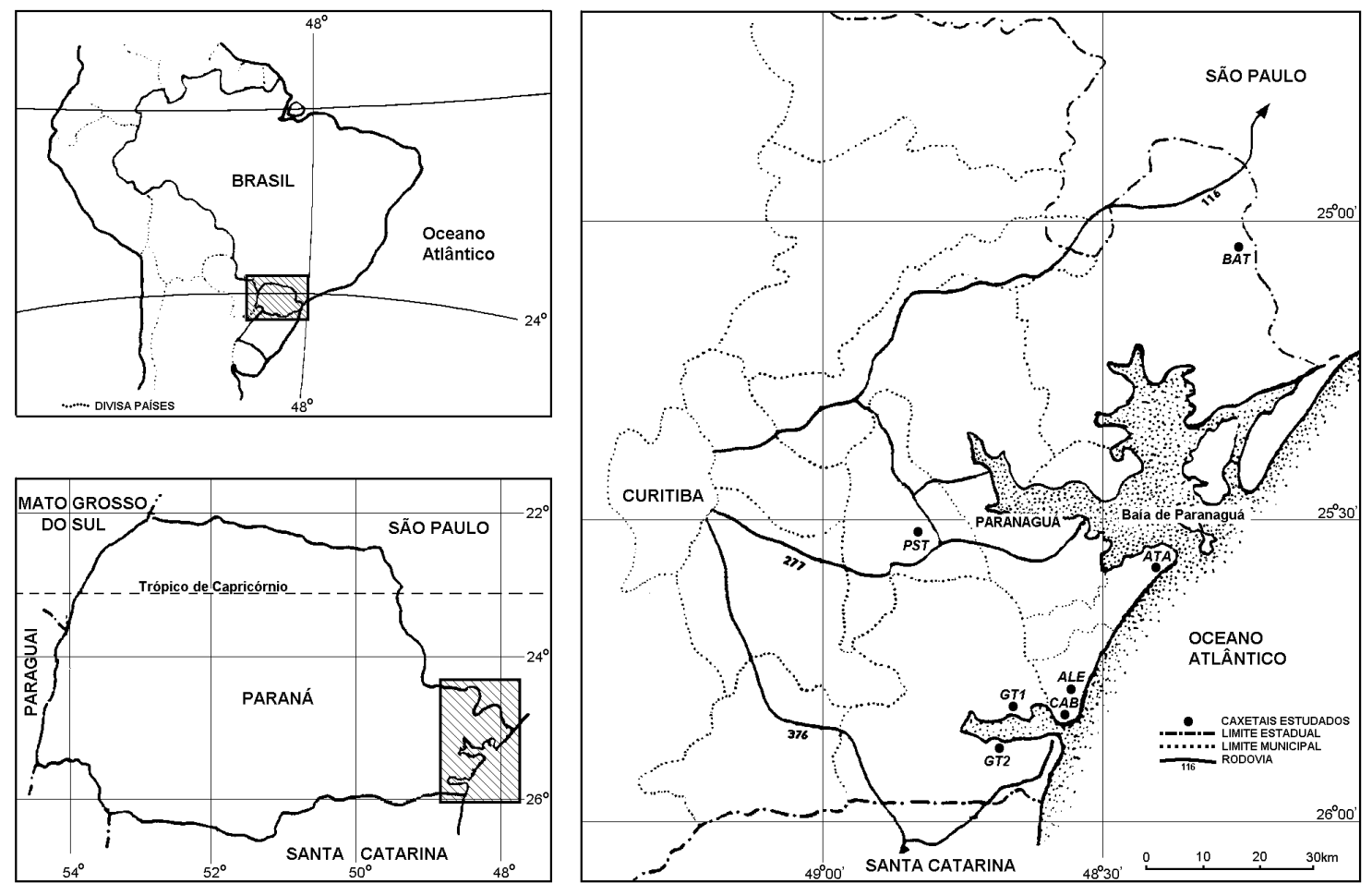

Figura 1: Mapa de localização dos caxetais estudados no estado do Paraná (ATA= Atami, ALE= AlexandraMatinhos, BAT= Batuva, CAB=Cabaraquara, GT1= Guaratuba 1, GT2 Guaratuba 2 e PST= PassaSete).

Figure 1: Location map of the caxeta sites studied in Parana state, Southern Brazil. 
Essa região do estado pode ser compartimentalizada em duas grandes superfícies, ambas de idade dominantemente quaternária. A primeira, mais próxima da Serra do Mar, é composta por sedimentos continentais, onde se encontram solos de textura média e argilosa, que têm sua gênese relacionada à sedimentação alúvio-coluvionar. Já a segunda superfície tem sua origem relacionada aos movimentos de transgressão e regressão marinha, composta por solos de textura essencialmente arenosa (Rachwall e Curcio, 2001).

O clima predominante é o do tipo Af, ou seja, tropical superúmido, sem estação seca, com temperaturas médias mensais superiores a $18^{\circ} \mathrm{C}$, isento de geadas e com precipitação média no mês mais seco acima de $60 \mathrm{~mm}$. A precipitação média anual é superior a 2000 mm (IAPAR, 1994).

Os caxetais estudados apresentam as seguintes peculiaridades:

- Alexandra-Matinhos (ALE): localiza-se no município de Matinhos $\left(25^{\circ} 46{ }^{\prime} 58^{\prime \prime S}\right.$ e $48^{\circ} 33^{\prime} 29^{\prime \prime} \mathrm{W}$ ), a $5 \mathrm{~m}$ s.n.m., ao longo da rodovia PR-508, a $4 \mathrm{~km}$ da sede do município e a $3,5 \mathrm{~km}$ da linha da costa. $\mathrm{O}$ ambiente é tipicamente fluvial, banhado pelo rio Indaial, afluente do rio Guaraguaçu, que é o principal da bacia hidrográfica da baía de Paranaguá, cujas nascentes são oriundas do complexo da serra da Prata. O relevo é plano e o solo é ORGANOSSOLO HÁPLICOS Fíbricos típico distrófico, com profundidade superior a $2 \mathrm{~m}$.

- Atami (ATA): localiza-se no município de Pontal do Paraná $\left(25^{\circ} 35^{\prime} 40^{\prime \prime} \mathrm{S}\right.$ e $\left.48^{\circ} 23^{\prime} 21^{\prime \prime} \mathrm{W}\right)$, a 3 m s.n.m., à margem da PR-412 e a $15 \mathrm{~km}$ da sede do município. O ambiente circundante é de restinga e este é, dentre os caxetais estudados, o mais próximo do mar, distando apenas $400 \mathrm{~m} \mathrm{da}$ linha da costa. Situa-se em área deprimida (intercordões), onde o abastecimento hídrico predominante ocorre por águas pluviais, sendo que o das fluviais decorre apenas da ação intermitente do riacho Penedo, além de não estar limitado por serras, como os outros. O relevo é plano e o solo é ORGANOSSOLO HÁPLICOS
Fíbricos típico distrófico, pouco profundo $(<1 \mathrm{~m})$, com substrato arenoso eutrófico.

- Batuva (BAT): localiza-se no município de Guaraqueçaba $\left(25^{\circ} 06^{\prime} 06^{\prime \prime S}\right.$ e $\left.48^{\circ} 12^{\prime} 32^{\prime \prime} \mathrm{W}\right)$, a $70 \mathrm{~m}$ s.n.m., muito próximo do limite geográfico com o estado de São Paulo. Dista $24 \mathrm{~km}$ tanto da sede do município, como da linha da costa, e $20 \mathrm{~km}$ da baía de Guaraqueçaba. É o mais interiorizado em relação ao ambiente de baía e o de maior altitude. Está sob influência do rio Guaraqueçaba, que faz parte da bacia hidrográfica da baía das Laranjeiras. Ocupa o vale formado pelas serras da Utinga, Negra, Gigante e Morato. O relevo é plano e o solo é ORGANOSSOLO HÁPLICOS Fíbricos típico distrófico, com profundidade entre 1 e $2 \mathrm{~m}$, assente sobre substrato franco-siltoso, distrófico.

- Cabaraquara (CAB): localiza-se no município de Matinhos (25050'22"S e $\left.48^{\circ} 34^{\prime} 26^{\prime \prime} \mathrm{W}\right)$, a $2-3 \mathrm{~m}$ s.n.m., próximo à rodovia PR-412, numa área contígua ao Iate Clube de Caiobá. Situa-se a $100 \mathrm{~m}$ da baía de Guaratuba, a $2 \mathrm{~km}$ da costa e a $15 \mathrm{~km}$ do estado de Santa Catarina, em ambiente tipicamente estuarino (flúvio-marinho). Esse caxetal está na base do morro de Cabaraquara, uma elevação da porção sul da serra da Prata, e é atravessado por um riacho de planície que sofre a influência das marés, por estar muito próximo ao nível do mar. O relevo é plano e o solo é ORGANOSSOLO HÁPLICOS Fíbricos típico eutrófico solódico, com profundidade entre 1 e $2 \mathrm{~m}$. As camadas orgânicas assentam-se sobre um substrato francosiltoso distrófico salino.

- Guaratuba 1 (GT1): localiza-se no município de Guaratuba (25 $44^{\circ}-25^{\circ} 55^{\prime} \mathrm{S}$ e $48^{\circ} 35^{\prime}-48^{\circ} 47^{\prime} \mathrm{W}$ ), em média a $5 \mathrm{~m}$ s.n.m., e a uma distância de $10 \mathrm{~km}$ da sede do município. Está sob influência da baía de Guaratuba, que recebe os sedimentos oriundos dos rios São João, Cubatão e Cubatãozinho. $\mathrm{O}$ ambiente é tipicamente estuarino, o relevo é plano e o solo é ORGANOSSOLO HÁPLICOS Fíbricos típico de profundidade variável (entre 0,5 e $1,5 \mathrm{~m})$. Apresenta estrutura e florística 
simplificadas, decorrente de alterações antrópicas.

- Guaratuba 2 (GT2): localiza-se também no município de Guaratuba e diferencia-se do GT1 apenas pelo fato de ser mais desenvolvido e de maior complexidade.

- Passa-Sete (PST): localiza-se no município de Morretes $\left(25^{\circ} 31^{\prime} 31^{\prime \prime} \mathrm{S}\right.$ e $\left.48^{\circ} 48^{\prime} 12^{\prime \prime} \mathrm{W}\right)$, a $10 \mathrm{~m}$ s.n.m., à margem da rodovia PR-408, a $2 \mathrm{~km}$ da sede do município. Dista $12 \mathrm{~km}$ da baía de Paranaguá e $39 \mathrm{~km}$ da linha da costa, sendo o mais afastado da orla marítima. É banhado pelo rio Passa-Sete, que integra a bacia hidrográfica do rio Nhundiaquara. É limitado pelas serras da Prata, Canasvieiras, da Igreja e Marumbi. O relevo é plano e o solo é ORGANOSSOLO HÁPLICOS Fíbricos típico distrófico, com profundidade entre 1 e $2 \mathrm{~m}$, assente sobre substrato muito argiloso, igualmente distrófico.

\section{Procedimento metodológico}

Foram utilizadas parcelas de $200 \mathrm{~m}^{2}$ (10 x $20 \mathrm{~m})$. O número de parcelas variou, em cada caxetal selecionado, de 8 a 20 (ALE $=10$; $\mathrm{ATA}=10 ; \quad \mathrm{BAT}=8 ; \quad \mathrm{CAB}=16 ; \quad \mathrm{GT} 1=15 ;$ GT2=20 e PST=13), em função de suas características estruturais e florísticas, sendo monitorado pela estabilização da curva espécie/área (curva do coletor). Todos os indivíduos arbóreos circunscritos às parcelas, com DAP (diâmetro à altura do peito) igual ou superior a $10 \mathrm{~cm}$, foram identificados, medidos seus diâmetros e estimadas suas alturas. A altura do ponto de inversão morfológica (bifurcação do fuste), a posição sociológica (estrato) em que ocorriam, as formas do fuste e da copa foram também obtidas de cada um dos indivíduos amostrados para elaboração de perfis esquemáticos, confeccionados com base em uma ou duas parcelas representativas da comunidade estudada. Quando um indivíduo apresentou múltiplos fustes, mediu-se somente aqueles que apresentavam um valor igual ou superior ao DAP mínimo estabelecido. A vegetação herbácea foi apenas descrita.

O material botânico coletado foi herborizado, identificado e depositado no Herbário Escola de Florestas Curitiba (EFC) e no Museu Botânico Municipal de Curitiba (MBM).

O processamento dos dados foi feito através do pacote de programas FITOPAC 1.0 (Shepherd, 1994), resultando na estimativa dos parâmetros de densidade, dominância e frequiência, além de valor de importância e índices de diversidade, de espécies raras e de similaridade (Mueller-Dombois e Ellenberg, 1974; Magurran, 1989).

\section{RESULTADOS E DISCUSSÃO}

Os caxetais, embora constituam quase sempre unidades fisionômica e estruturalmente homogêneas, sob o ponto de vista florístico são diversos. No presente estudo, mesmo optando pela inclusão somente de indivíduos com valores de DAP igual ou superior a 10 $\mathrm{cm}$, o que limita a expressão da florística e dos descritores fitossociológicos, foram encontradas mais de 100 espécies arbóreas, vinculadas a 35 famílias, onde, evidentemente, além da família Bignoniaceae, a qual pertence Tabebuia cassinoides, somente Fabaceae e Myrtaceae foram recorrentes em todos os locais amostrados. Com freqüência mais baixa, mas também importantes nesses ambientes, apareceram espécies de Moraceae, Arecaceae, Aquifoliaceae, Melastomataceae, Mimosaceae, Clusiaceae e Euphorbiaceae (Figura 2 e Tabela 1). 


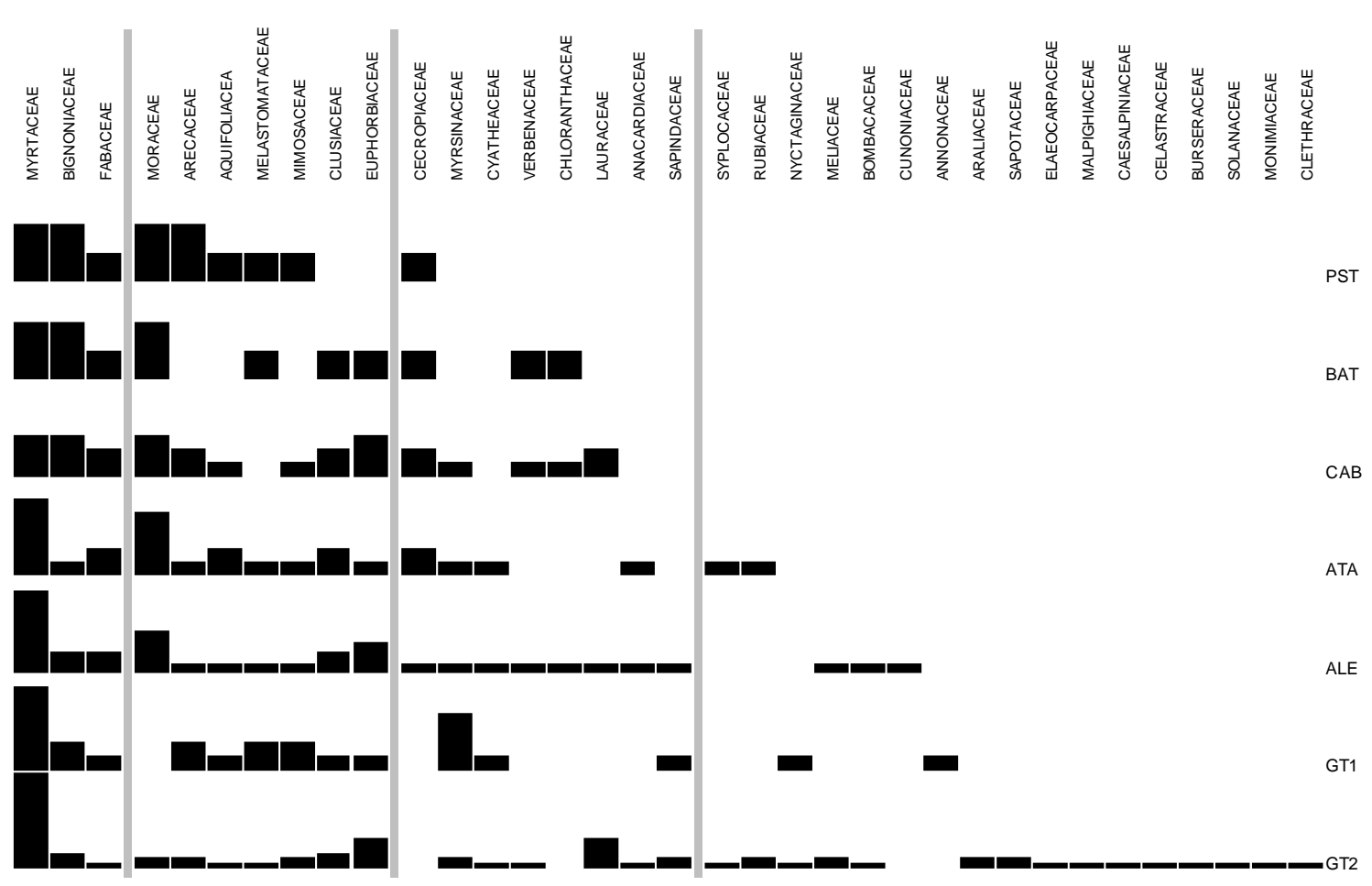

Figura 2: Distribuição de espécies por família botânica nos caxetais estudados.

Figure 2: Species distribution per family in the studied sites.

Tabela 1: Relação de famílias e espécies arbóreas amostradas nos caxetais estudados.

Table 1: $\quad$ List of families and species surveyed in the sites studied.

\begin{tabular}{|c|c|c|c|c|c|c|c|c|}
\hline FAMÍLIAS & ESPÉCIES & PST & BAT & CAB & ATA & ALE & GT1 & GT2 \\
\hline ANACARDIACEAE & Tapirira guianensis Aubl. & & & & $\mathrm{X}$ & $\mathrm{X}$ & & $\mathrm{X}$ \\
\hline ANNONACEAE & Rollinia rugulosa Schlecht. & & & & & & $\mathrm{X}$ & \\
\hline \multirow[t]{3}{*}{ AQUIFOLIACEAE } & Ilex dumosa Reiss. & $\mathrm{X}$ & & $\mathrm{X}$ & $\mathrm{X}$ & $\mathrm{X}$ & $\mathrm{X}$ & \\
\hline & Ilex psammophila Mart. ex Reiss. & & & & & & & $\mathrm{X}$ \\
\hline & Ilex theezans Mart. & & & & $\mathrm{X}$ & & & \\
\hline \multirow[t]{2}{*}{ ARALIACEAE } & Didymopanax angustissimum March. & & & & & & & $\mathrm{X}$ \\
\hline & Didymopanax morototoni Decne. \& Planch. & & & & & & & $\mathrm{X}$ \\
\hline \multirow[t]{3}{*}{ ARECACEAE } & Euterpe edulis Mart. & $\mathrm{X}$ & & $\mathrm{X}$ & & & $\mathrm{X}$ & \\
\hline & Geonoma schottiana Mart. & & & & & & & $\mathrm{X}$ \\
\hline & Syagrus romanzoffiana (Cham.) Glassm. & $\mathrm{X}$ & & $\mathrm{X}$ & $\mathrm{X}$ & $\mathrm{X}$ & $\mathrm{X}$ & $\mathrm{X}$ \\
\hline \multirow[t]{3}{*}{ BIGNONIACEAE } & Jacaranda puberula Cham. & & & $\mathrm{X}$ & & & & $\mathrm{X}$ \\
\hline & Tabebuia cassinoides $(\mathrm{Lam}.) \mathrm{DC}$ & $\mathrm{X}$ & $\mathrm{X}$ & $\mathrm{X}$ & $\mathrm{X}$ & $\mathrm{X}$ & $\mathrm{X}$ & $\mathrm{X}$ \\
\hline & Tabebuia umbellata (Sond.) Sandw. & $\mathrm{X}$ & $\mathrm{X}$ & $\mathrm{X}$ & & $\mathrm{X}$ & $\mathrm{X}$ & $\mathrm{X}$ \\
\hline BOMBACACEAE & Pseudobombax grandiflorum (Cav.) A. Robyns & & $\mathrm{X}$ & & & $\mathrm{X}$ & & $\mathrm{X}$ \\
\hline BURSERACEAE & Protium sp. & & & & & & & $\mathrm{X}$ \\
\hline CAESALPINIACEAE & Senna multijuga (L.C. Rich.) Irw. \& Barn. & & & & & & & $\mathrm{X}$ \\
\hline \multirow[t]{3}{*}{ CECROPIACEAE } & Cecropia pachystachya Trec. & $\mathrm{X}$ & $\mathrm{X}$ & & & $\mathrm{X}$ & & \\
\hline & Coussapoa microcarpa (Schott.) Rizzini & & & $\mathrm{X}$ & $\mathrm{X}$ & & & \\
\hline & Coussapoa schottii Miq. & & & $\mathrm{X}$ & $\mathrm{X}$ & & & \\
\hline CELASTRACEAE & Maytenus alaternoides Reiss. & & & & & & & $\mathrm{X}$ \\
\hline CHLORANTHACEAE & Hedyosmum brasiliense Mart. ex Miq. & & $\mathrm{X}$ & & & $\mathrm{X}$ & & \\
\hline CLETHRACEAE & Clethra scabra Pers. & & & & & & & $\mathrm{X}$ \\
\hline \multirow[t]{3}{*}{ CLUSIACEAE } & Calophyllum brasiliense Camb. & & & $\mathrm{X}$ & $\mathrm{X}$ & $\mathrm{X}$ & $\mathrm{X}$ & $\mathrm{X}$ \\
\hline & Clusia criuva Camb. & & $\mathrm{X}$ & $\mathrm{X}$ & $\mathrm{X}$ & $\mathrm{X}$ & & $\mathrm{X}$ \\
\hline & Garcinia gardneriana (Planch. \& Triana) Zappi. & & & & & & & $\mathrm{X}$ \\
\hline CUNONIACEAE & Weinmannia paulliniaefolia Pohl ex Ser. & & & & & $\mathrm{X}$ & & \\
\hline \multirow[t]{2}{*}{ CYATHEACEAE } & Alsophila sp. & & & & $\mathrm{X}$ & $\mathrm{X}$ & & \\
\hline & Trichipteris atrovirens (Langsd. \& Fisch.) Tryon & & & & & & $\mathrm{X}$ & $\mathrm{X}$ \\
\hline
\end{tabular}

Continua 
Continuação

FAMÍLIAS

ELAEOCARPACEAE

ESPÉCIES

\begin{tabular}{|l|l|l|l|l|l|c|} 
PST & BAT & CAB & ATA & ALE & GT1 & GT2 \\
\hline
\end{tabular} EUPHORBIACEAE

Sloanea guianensis (Aubl.) Benth.

Alchornea glandulosa Poepp. \& Endl.

Alchornea sidifolia M. Arg.

Alchornea triplinervia (Spreng.) M. Arg.

Aparisthmium cordatum (Juss.) Baill.

Hyeronima alchorneoides Fr. All.

Pera glabrata Poepp. ex Baill.

Pera sp.

Sapium glandulatum (Vell.) Pax.

\begin{tabular}{|c|c|c|c|c|c|c|c|c|}
\hline & Sapium glandulatum (Vell.) Pax. & & & $\mathrm{X}$ & & & $\mathrm{X}$ & $\mathrm{X}$ \\
\hline \multirow[t]{2}{*}{ FABACEAE } & Andira anthelmia (Vell.) J. F. Macbr. & & & $\mathrm{X}$ & $\mathrm{X}$ & $\mathrm{X}$ & $\mathrm{X}$ & $\mathrm{X}$ \\
\hline & Platymiscium floribundum Vog. & $\mathrm{X}$ & $\mathrm{X}$ & $\mathrm{X}$ & $\mathrm{X}$ & $\mathrm{X}$ & & \\
\hline \multirow[t]{8}{*}{ LAURACEAE } & Nectandra megapotamica (Spreng.) Mez & & & & & & & $\mathrm{X}$ \\
\hline & Nectandra rigida (Kunth) Nees & & & & & & & $\mathrm{X}$ \\
\hline & Nectandra sp. & & & $\mathrm{X}$ & & & & $\bar{X}$ \\
\hline & Ocotea aciphylla (Nees) Mez & & & & & & & $\mathrm{X}$ \\
\hline & Ocotea pulchella Mez & & & $\mathrm{X}$ & & & & $\mathrm{X}$ \\
\hline & Ocotea $\mathrm{sp}$ & & & & & $\mathrm{X}$ & & $\mathrm{X}$ \\
\hline & Lauraceae 1 & & & & & & & $\mathrm{X}$ \\
\hline & Lauraceae 2 & & & & & & & $\mathrm{X}$ \\
\hline MALPIGHIACEAE & Byrsonima niedenzuiana Skottsb. & & & & & & & $\mathrm{X}$ \\
\hline \multirow[t]{2}{*}{ MELASTOMATACEAE } & Miconia sp. & & & & & & $\mathrm{X}$ & \\
\hline & Tibouchina multiceps (Naud.) Cogn. & $\mathrm{X}$ & $\mathrm{X}$ & & $\mathrm{X}$ & $\mathrm{X}$ & $\mathrm{X}$ & $\mathrm{X}$ \\
\hline \multirow[t]{2}{*}{ MELIACEAE } & Cabralea canjerana (Vell.) Mart. & & & & & & & $\mathrm{X}$ \\
\hline & Guarea macrophylla Vahl & & & & & $\mathrm{X}$ & & $\mathrm{X}$ \\
\hline \multirow[t]{3}{*}{ MIMOSACEAE } & Inga edulis Mart. & $\mathrm{X}$ & & $\mathrm{X}$ & $\mathrm{X}$ & $\mathrm{X}$ & $\mathrm{X}$ & $\mathrm{X}$ \\
\hline & Inga marginata Will. & & & & & & $\mathrm{X}$ & \\
\hline & Inga sessilis Benth. & & & & & & & $\mathrm{X}$ \\
\hline MONIMIACEAE & Mollinedia uleana Perkins & & & & & & & $\mathrm{X}$ \\
\hline \multirow[t]{7}{*}{ MORACEAE } & Ficus adhatodifolia Schott. ex Spreng. & & $\mathrm{X}$ & $\mathrm{X}$ & & $\mathrm{X}$ & & \\
\hline & Ficus luschnathiana (Miq.) Miq. & $\mathrm{X}$ & & $\mathrm{X}$ & $\mathrm{X}$ & $\mathrm{X}$ & & $\mathrm{X}$ \\
\hline & Ficus sp. & $\mathrm{X}$ & & $\mathrm{X}$ & $\mathrm{X}$ & & & $\mathrm{X}$ \\
\hline & Moraceae 1 & & & & $\mathrm{X}$ & $\mathrm{X}$ & & \\
\hline & Moraceae 2 & & & & $\mathrm{X}$ & $\mathrm{X}$ & & \\
\hline & Moraceae 3 & & $\mathrm{X}$ & & $\mathrm{X}$ & & & \\
\hline & Moraceae 4 & & & & $\mathrm{X}$ & & & \\
\hline \multirow[t]{4}{*}{ MYRSINACEAE } & Myrsine parvifolia (DC.) Mez & & & & & & $\mathrm{X}$ & $\mathrm{X}$ \\
\hline & Myrsine umbellata (Mart.) Mez & & & & & & $\mathrm{X}$ & $\mathrm{X}$ \\
\hline & Myrsine sp. 1 & & & $\mathrm{X}$ & $\mathrm{X}$ & $\mathrm{X}$ & $\mathrm{X}$ & \\
\hline & Myrsine sp. 2 & & & & & & $\mathrm{X}$ & \\
\hline \multirow{23}{*}{ MYRTACEAE } & Calycorectes sp. 1 & & & & & & $\mathrm{X}$ & $\mathrm{X}$ \\
\hline & Calycorectes sp. 2 & & & & & & & $\mathrm{X}$ \\
\hline & Calycorectes sp. 3 & & & & & & & $\mathrm{X}$ \\
\hline & Calyptranthes conccina DC. & & & & & & & $\mathrm{X}$ \\
\hline & Calyptranthes lanceolata Berg & & & & & & & $X$ \\
\hline & Calyptranthes lucida Mart. ex DC. & & $\mathrm{X}$ & $\mathrm{X}$ & $\mathrm{X}$ & $\mathrm{X}$ & & \\
\hline & Calyptranthes sp. 1 & & & & $\mathrm{X}$ & $\mathrm{X}$ & & \\
\hline & Calyptranthes sp. 2 & & & & & $\mathrm{X}$ & & \\
\hline & Eugenia cereja C. D. Legrand & & & & & & & $\mathrm{X}$ \\
\hline & Eugenia obovata Poir. & & & & & & & $\mathrm{X}$ \\
\hline & Eugenia sulcata Spring ex Mart. & & & & & & & $\mathrm{X}$ \\
\hline & Eugenia umbelliflora Berg & & & & & & $\mathrm{X}$ & $\mathrm{X}$ \\
\hline & Gomidesia palustris (DC.) Legr. & & & & & & $\mathrm{X}$ & $\mathrm{X}$ \\
\hline & Marlierea eugeniopsoides Camb. & & & & & & & $\mathrm{X}$ \\
\hline & Marlierea obscura Berg & & & & & $\mathrm{X}$ & & \\
\hline & Marlierea parviflora Berg & & & & & & & $\mathrm{X}$ \\
\hline & Marlierea tomentosa Camb. & $\mathrm{X}$ & $\mathrm{X}$ & & & $\mathrm{X}$ & $\mathrm{X}$ & $X$ \\
\hline & Marlierea sp. & & & & & & & $\mathrm{X}$ \\
\hline & Myrcia acuminatissima Berg & & & & & & & $\mathrm{X}$ \\
\hline & Myrcia insularis Gardn. & & & & $\mathrm{X}$ & $\mathrm{X}$ & & \\
\hline & Myrcia multiflora DC. & & & $\mathrm{X}$ & $\mathrm{X}$ & $\mathrm{X}$ & $\mathrm{X}$ & $\mathrm{X}$ \\
\hline & Myrcia pubipetala Miq. & & & & & & & $\mathrm{X}$ \\
\hline & Psidium cattleianum Sabine & $\mathrm{X}$ & & $\mathrm{X}$ & $\mathrm{X}$ & $\mathrm{X}$ & $\mathrm{X}$ & $\mathrm{X}$ \\
\hline
\end{tabular}

\begin{tabular}{|l|c|c|c|c|c|} 
& PST & BAT & CAB & ATA & A \\
& & & & & \\
& & & $\mathrm{X}$ & & \\
& & & $\mathrm{X}$ & & \\
\hline
\end{tabular}

\begin{tabular}{|l|l|l|}
\hline & & $\mathrm{X}$ \\
\hline $\mathrm{X}$ & & \\
\hline $\mathrm{X}$ & & $\mathrm{X}$ \\
\hline
\end{tabular}

\begin{tabular}{|l|l|l|}
\hline & & \\
\hline
\end{tabular}

\begin{tabular}{l|l|l} 
& $\mathrm{X}$ & $\mathrm{X}$ \\
\hline
\end{tabular}

\begin{tabular}{|l|l|l|}
\hline & & $\mathrm{X}$ \\
\hline & & $\mathrm{X}$ \\
\hline
\end{tabular}


Conclusão

\begin{tabular}{|c|c|c|c|c|c|c|c|c|}
\hline FAMÍLIAS & ESPÉCIES & PST & BAT & CAB & ATA & ALE & GT1 & GT2 \\
\hline & Myrtaceae 1 & & & & & & & $\mathrm{X}$ \\
\hline & Myrtaceae 2 & & & & & & & $\mathrm{X}$ \\
\hline \multirow[t]{2}{*}{ NYCTAGINACEAE } & Guapira opposita (Vell.) Reitz & & & & & & $\mathrm{X}$ & $\mathrm{X}$ \\
\hline & Neea sp. & & & & $\mathrm{X}$ & & & \\
\hline \multirow[t]{2}{*}{ RUBIACEAE } & Amaioua guianensis Aubl. & & & & & & & $\mathrm{X}$ \\
\hline & Posoqueria latifolia (Rudge) Roem. \& Schult. & & & & & & & $\mathrm{X}$ \\
\hline \multirow[t]{2}{*}{ SAPINDACEAE } & Cupania oblongifolia Mart. & & & & & & & $\mathrm{X}$ \\
\hline & Matayba guianensis Aubl. & & & & & $\mathrm{X}$ & $\mathrm{X}$ & $\mathrm{X}$ \\
\hline \multirow[t]{2}{*}{ SAPOTACEAE } & Pouteria caimito (Ruiz \& Pav.) Radlk. & & & & & & & $\mathrm{X}$ \\
\hline & Pouteria sp. & & & & & & & $\mathrm{X}$ \\
\hline SOLANACEAE & Solanum sp. & & & & & & & $\mathrm{X}$ \\
\hline \multirow[t]{2}{*}{ SYMPLOCACEAE } & Symplocos nitidiflora Brand & & & & $\mathrm{X}$ & & & \\
\hline & Symplocos uniflora (Pohl.) Benth. & & & & & & & $\mathrm{X}$ \\
\hline \multirow[t]{2}{*}{ VERBENACEAE } & Aegiphila sellowiana Cham. & & & & & & & $\mathrm{X}$ \\
\hline & Cytharexylum myrianthum Cham. & & $\mathrm{X}$ & $\mathrm{X}$ & & $\mathrm{X}$ & & \\
\hline
\end{tabular}

$\mathrm{O}$ número de famílias, gêneros e espécies arbóreas desses ambientes é, por outro lado, proporcionalmente pequeno em relação aos encontrados em outros ecossistemas florestais de influência atlântica na região (Menezes-Silva, 1990; Guapyassú, 1994; Lolis, 1996; Athayde, 1997; MenezesSilva, 1998) em razão, principalmente, das restrições pedológicas. Os solos, essencialmente hidromórficos (ORGANOSSOLOS), provocam um estabelecimento seletivo da vida vegetal, fazendo com que as espécies que ali crescem desenvolvam adaptações que lhes permitam suportar tais condições. As raízes respiratórias geniculadas (Kuniyoshi, 1993) de Tabebuia cassinoides constituem, nesse caso, o melhor exemplo de adaptação aos altos níveis de saturação hídrica. Em outras unidades pedológicas de planície (ESPODOSSOLOS e NEOSSOLOS), e principalmente nas de encosta (LATOSSOLOS, ARGISSOLOS e CAMBISSOLOS), as condições pedológicas são comparativamente muito mais favoráveis, o que justifica uma florística mais rica. Também a exploração constante dessas áreas pode interferir na composição florística, pois deve dificultar o estabelecimento de indivíduos, assim como alterar quantitativa e qualitativamente a composição natural das espécies.

\section{Caracterização dos caxetais estudados}

Fisionomicamente, os caxetais guardam entre si uma semelhança que se deve ao predomínio de Tabebuia cassinoides. Numa avaliação mais detalhada, porém, pode-se perceber diferenças estruturais e florísticas, que constituem indicações de seus níveis de desenvolvimento sucessional ou de seu histórico de exploração.

Dentre os locais estudados, os caxetais Passa-Sete e Batuva são bons exemplos da decorrência de explorações cíclicas ou de alterações no regime hídrico dos solos, provocadas pela abertura de canais de drenagem. Esses procedimentos, principalmente a exploração, concorrem para uma florística mais simplificada onde se manifesta o predomínio de Tabebuia cassinoides, circunstancialmente associada com Tabebuia umbellata e Marlierea tomentosa (Tabelas 2 e 3). São unidades que apresentam apenas um estrato arbóreo bem diferenciado, com altura média entre 8 e $12 \mathrm{~m}$, além de arvoretas que compõem o sub-bosque. Os valores de dominância são baixos (31,4 e $36,4 \mathrm{~m}^{2} / \mathrm{ha}$ ) em função do grande número de indivíduos com diâmetros finos. 
Tabela 2: Valores fitossociológicos do caxetal Passa-Sete.

Table 2: Phytossociological results of the Passa-Sete site.

\begin{tabular}{|c|c|c|c|c|c|c|c|}
\hline \multirow{2}{*}{ ESPÉCIES } & \multicolumn{2}{|c|}{ DENSIDADE } & \multicolumn{2}{|c|}{ FREQÜÊNCIA } & \multicolumn{2}{|c|}{ DOMINÂNCIA } & \multirow{2}{*}{ VI } \\
\hline & Abs. ( $\left.\mathrm{N}^{\mathrm{o}} / \mathrm{ha}\right)$ & Rel. (\%) & Abs. (\%) & Rel. (\%) & Abs. $\left(\mathrm{m}^{2} / \mathrm{ha}\right)$ & Rel. (\%) & \\
\hline Cecropia pachystachya & 4,00 & 0,25 & 7,69 & 2,00 & 0,06 & 0,18 & 2,43 \\
\hline Euterpe edulis & 8,00 & 0,50 & 15,38 & 4,00 & 0,05 & 0,18 & 4,68 \\
\hline Ficus sp. & 4,00 & 0,25 & 7,69 & 2,00 & 0,11 & 0,35 & 2,61 \\
\hline Ficus luschnathiana & 15,00 & 0,93 & 30,77 & 8,00 & 0,44 & 1,39 & 10,32 \\
\hline Ilex dumosa & 4,00 & 0,25 & 7,69 & 2,00 & 0,13 & 0,41 & 2,67 \\
\hline Inga edulis & 8,00 & 0,50 & 15,38 & 4,00 & 0,17 & 0,55 & 5,04 \\
\hline Marlierea tomentosa & 31,00 & 1,92 & 53,85 & 14,00 & 0,17 & 0,54 & 16,47 \\
\hline Platymiscium floribundum & 8,00 & 0,50 & 15,38 & 4,00 & 0,15 & 0,49 & 4,98 \\
\hline Psidium cattleianum & 8,00 & 0,50 & 15,38 & 4,00 & 0,06 & 0,18 & 4,68 \\
\hline Syagrus romanzoffiana & 16,00 & 0,99 & 30,77 & 8,00 & 0,34 & 1,08 & 10,08 \\
\hline Tabebuia cassinoides & 1365,00 & 84,78 & 100,00 & 26,00 & 28,22 & 89,73 & 200,49 \\
\hline Tabebuia umbellata & 39,00 & 2,42 & 46,15 & 12,00 & 0,36 & 1,14 & 15,57 \\
\hline Tibouchina multiceps & 100,00 & 6,21 & 38,46 & 10,00 & 1,19 & 3,78 & 19,98 \\
\hline TOTAIS & 1610,00 & 100,00 & 384,59 & 100,00 & 31,45 & 100,00 & 300,00 \\
\hline
\end{tabular}

(Abreviaturas: Abs. = absoluta; Rel. $=$ relativa e VI $=$ valor de importância)

Tabela 3: Valores fitossociológicos do caxetal Batuva.

Table 3: Phytossociological results of the Batuva site.

\begin{tabular}{|c|c|c|c|c|c|c|c|}
\hline \multirow{2}{*}{ ESPÉCIES } & \multicolumn{2}{|c|}{ DENSIDADE } & \multicolumn{2}{|c|}{ FREQÜÊNCIA } & \multicolumn{2}{|c|}{ DOMINÂNCIA } & \multirow{2}{*}{ VI } \\
\hline & Abs. $\left.\mathrm{N}^{\mathrm{o}} / \mathrm{ha}\right)$ & Rel. (\%) & Abs.(\%) & Rel.(\%) & Abs. $\left(\mathrm{m}^{2} / \mathrm{ha}\right)$ & Rel.(\%) & \\
\hline Calyptranthes lucida & 6,00 & 0,31 & 12,50 & 2,22 & 0,04 & 0,11 & 2,64 \\
\hline Cecropia pachystachya & 81,00 & 4,15 & 62,50 & 11,11 & 0,65 & 1,79 & 17,04 \\
\hline Cytharexylum myrianthum & 6,00 & 0,31 & 12,50 & 2,22 & 0,06 & 0,16 & 2,70 \\
\hline Clusia criuva & 19,00 & 0,97 & 25,00 & 4,44 & 0,13 & 0,35 & 5,76 \\
\hline Ficus adhatodifolia & 13,00 & 0,67 & 25,00 & 4,44 & 0,21 & 0,58 & 5,67 \\
\hline Hedyosmum brasiliense & 13,00 & 0,67 & 25,00 & 4,44 & 0,09 & 0,25 & 5,37 \\
\hline Marlierea tomentosa & 63,00 & 3,23 & 62,50 & 11,11 & 0,53 & 1,46 & 15,81 \\
\hline Platymiscium floribundum & 13,00 & 0,67 & 12,50 & 2,22 & 0,52 & 1,43 & 4,32 \\
\hline Pseudobombax grandiflorum & 25,00 & 1,28 & 37,50 & 6,67 & 0,56 & 1,54 & 9,48 \\
\hline Tabebuia cassinoides & 1331,00 & 68,22 & 100,00 & 17,79 & 27,20 & 74,81 & 160,83 \\
\hline Tabebuia umbellata & 281,00 & 14,40 & 100,00 & 17,79 & 4,60 & 12,65 & 44,85 \\
\hline Tibouchina multiceps & 19,00 & 0,97 & 25,00 & 4,44 & 0,15 & 0,41 & 5,82 \\
\hline Moraceae 3 & 81,00 & 4,15 & 62,50 & 11,11 & 1,62 & 4,46 & 19,71 \\
\hline TOTAIS & 1951,00 & 100,00 & 562,50 & 100,00 & 36,36 & 100,00 & 300,00 \\
\hline
\end{tabular}

(Abreviaturas: Abs. = absoluta; Rel. = relativa e VI = valor de importância)

Apesar da baixa diversidade da vegetação arbórea, são ambientes extremamente ricos em formas de vida epífitas e terrestres, que povoam o sub-bosque. Hedychium coronarium (Zingiberaceae), Costus arabicus (Costaceae), Philodendron spp. (Araceae), Calathea sp. (Marantaceae), Bactris sp. (Arecaceae), Polypodium spp. (Polypodiaceae), Piper spp. (Piperaceae), Begonia spp. (Begoniaceae), Musa sp. (Musaceae), Smilax sp. (Smilacaceae), Selaginella sp. (Selaginellaceae) e Lygodium sp. (Schizaeaceae), além de representantes das famílias Poaceae, Cyperaceae e Rubiaceae, são comuns nesses ambientes (Figuras 3 e 4 ).

O caxetal Cabaraquara, situado em área adjacente a um taboal (formação exclusiva de Typha domingensis - Typhaceae), é constituído de dois estratos arbóreos, com um dossel entre 7 e $12 \mathrm{~m}$ de altura. Como nos casos anteriores,
Tabebuia cassinoides predomina em ambos os estratos, representando $61 \%$ dos indivíduos amostrados e $54 \%$ da área basal total (Tabela 4). Psidium cattleianum foi a segunda espécie de maior expressão nessa unidade, ocorrendo de forma mais efetiva no espaço oligofótico, onde Ficus luschnathiana alcançou também boa expressão. Nectandra sp., Ficus adhatodifolia, Ficus sp., Tabebuia umbellata, Alchornea glandulosa e Alchornea sidifolia foram encontradas apenas no estrato superior. Digno de registro é a ocorrência de Calophyllum brasiliense, cuja presença, quando formando agregados importantes na planície litorânea do estado, remete à suposição de estar estabelecida em ambientes sujeitos ao refluxo subsuperficial de marés (comunicação oral de Gustavo Ribas Curcio - pesquisador EMBRAPA Florestas, Colombo/PR). 


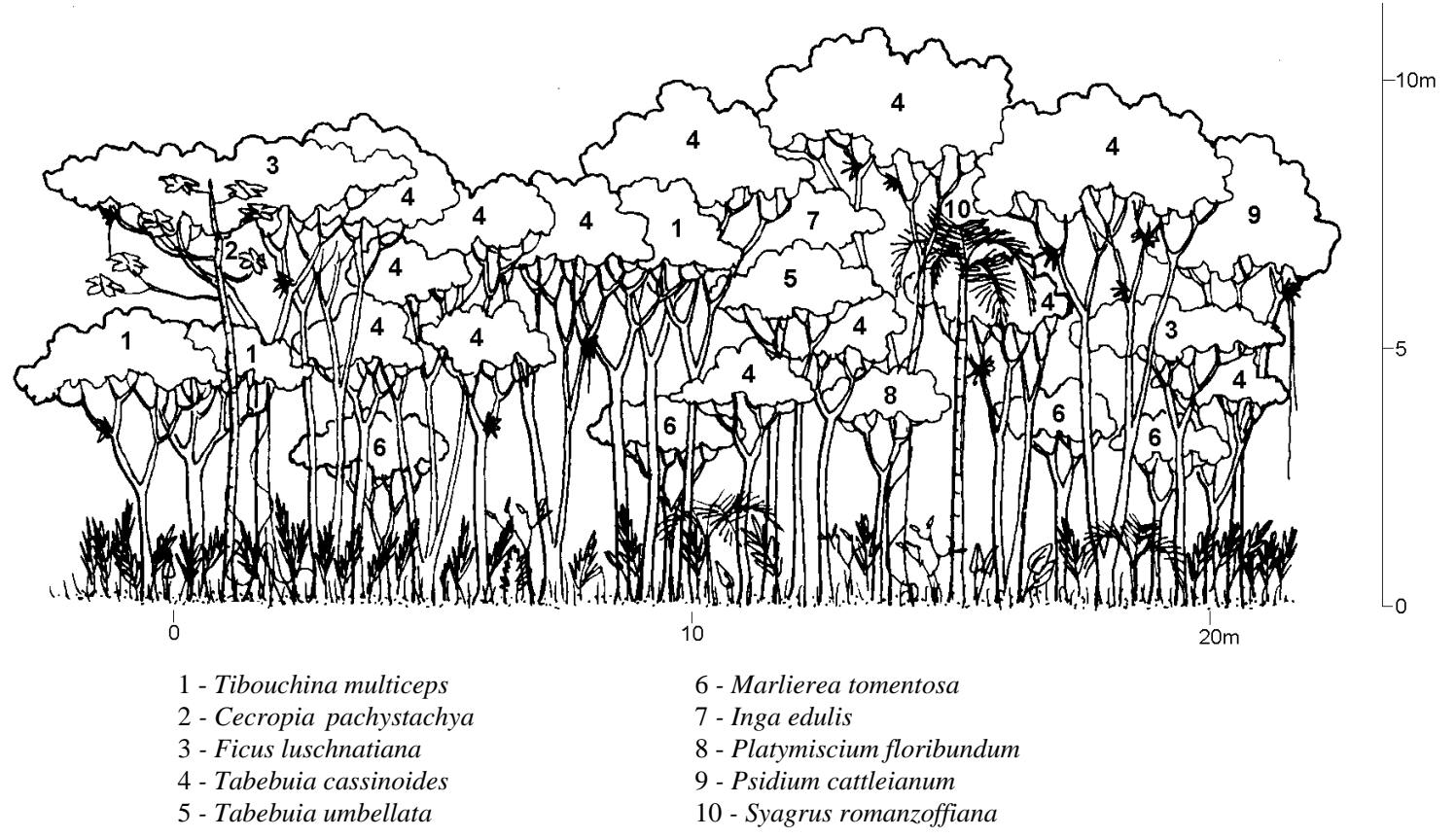

Figura 3: Perfil esquemático de um trecho do caxetal Passa-Sete.

Figure 3: Profile of the Passa-Sete site.

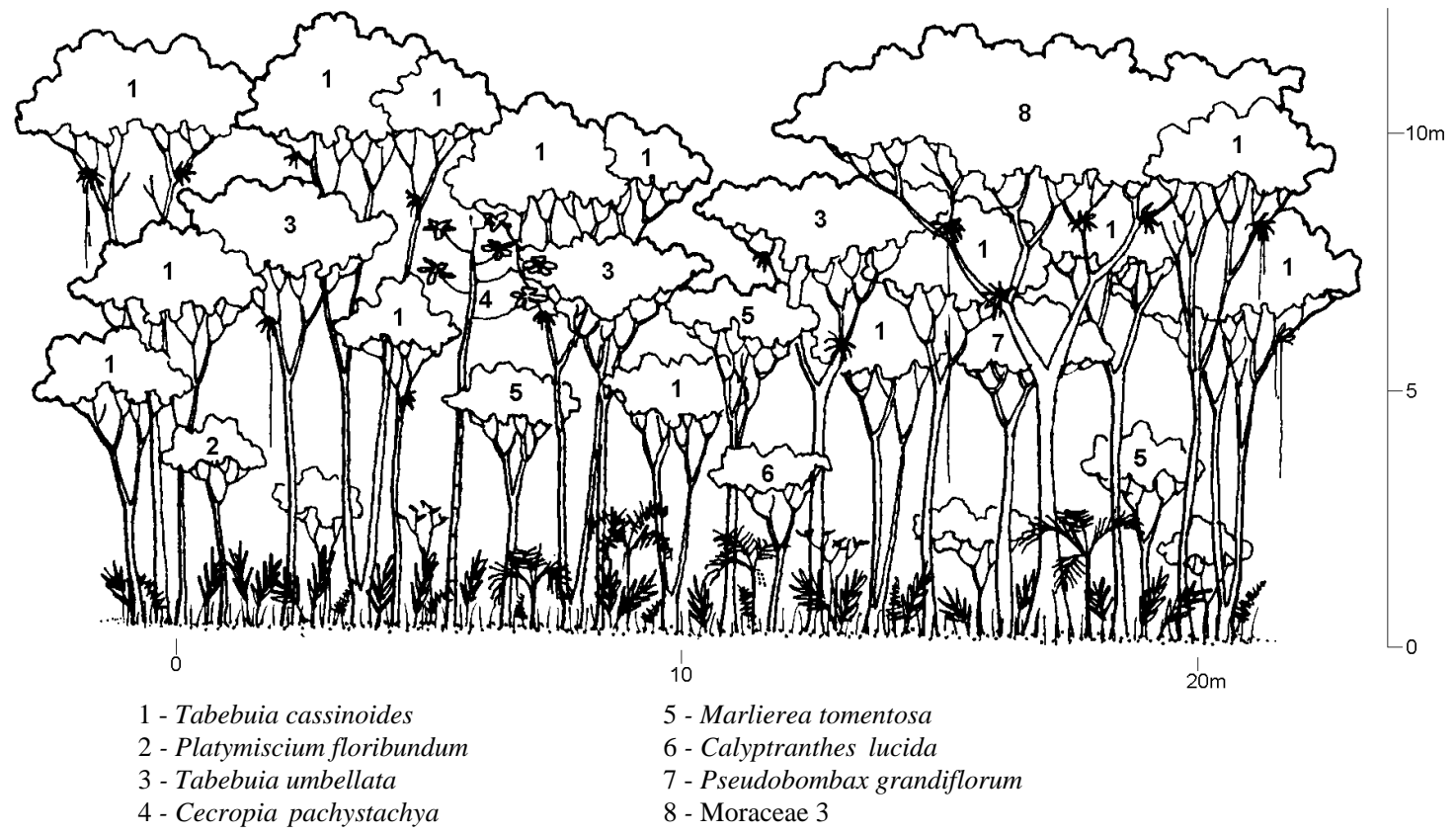

Figura 4: Perfil esquemático de um trecho do caxetal Batuva.

Figure 4: Profile of the Batuva site. 
Tabela 4: Valores fitossociológicos do caxetal Cabaraquara.

Table 4: $\quad$ Phytossociological results of the Cabaraquara site.

\begin{tabular}{|c|c|c|c|c|c|c|c|}
\hline \multirow[b]{2}{*}{ ESPÉCIES } & \multicolumn{2}{|c|}{ DENSIDADE } & \multicolumn{2}{|c|}{ FREQÜÊENCIA } & \multicolumn{2}{|c|}{ DOMINÂNCIA } & \multirow[b]{2}{*}{ VI } \\
\hline & $\begin{array}{c}\text { Abs. } \\
\left(\mathrm{N}^{\mathrm{o}} / \mathrm{ha}\right)\end{array}$ & $\begin{array}{l}\text { Rel. } \\
(\%)\end{array}$ & $\begin{array}{l}\text { Abs. } \\
(\%)\end{array}$ & $\begin{array}{l}\text { Rel. } \\
(\%)\end{array}$ & $\begin{array}{c}\text { Abs. } \\
\left(\mathrm{m}^{2} / \mathrm{ha}\right)\end{array}$ & $\begin{array}{l}\text { Rel. } \\
(\%)\end{array}$ & \\
\hline Alchornea glandulosa & 7,00 & 0,51 & 6,25 & 0,92 & 0,20 & 0,41 & 1,83 \\
\hline Alchornea sidifolia & 3,00 & 0,22 & 6,25 & 0,92 & 0,28 & 0,57 & 1,71 \\
\hline Andira anthelmia & 3,00 & 0,22 & 6,25 & 0,92 & 0,07 & 0,14 & 1,29 \\
\hline Calophyllum brasiliense & 27,00 & 1,95 & 31,25 & 4,59 & 2,17 & 4,46 & 11,01 \\
\hline Calyptranthes lucida & 10,00 & 0,72 & 18,75 & 2,75 & 0,20 & 0,40 & 3,87 \\
\hline Cytharexylum myrianthum & 34,00 & 2,45 & 25,00 & 3,67 & 1,79 & 3,67 & 9,78 \\
\hline Clusia criuva & 14,00 & 1,01 & 18,75 & 2,75 & 0,44 & 0,90 & 4,65 \\
\hline Coussapoa microcarpa & 6,00 & 0,43 & 6,25 & 0,92 & 0,43 & 0,89 & 2,25 \\
\hline Coussapoa schottii & 3,00 & 0,22 & 6,25 & 0,92 & 0,02 & 0,04 & 1,17 \\
\hline Euterpe edulis & 44,00 & 3,18 & 56,25 & 8,25 & 0,46 & 0,95 & 12,39 \\
\hline Ficus sp. & 7,00 & 0,51 & 12,50 & 1,83 & 0,57 & 1,16 & 3,51 \\
\hline Ficus adhatodifolia & 22,00 & 1,59 & 31,25 & 4,59 & 2,16 & 4,43 & 10,62 \\
\hline Ficus luschnathiana & 49,00 & 3,54 & 68,75 & 10,09 & 4,88 & 10,02 & 23,64 \\
\hline Hedyosmum brasiliense & 19,00 & 1,37 & 31,25 & 4,59 & 0,38 & 0,79 & 6,75 \\
\hline Ilex dumosa & 32,00 & 2,31 & 25,00 & 3,67 & 0,26 & 0,52 & 6,51 \\
\hline Inga edulis & 23,00 & 1,66 & 18,75 & 2,75 & 0,63 & 1,31 & 5,73 \\
\hline Jacaranda puberula & 10,00 & 0,72 & 18,75 & 2,75 & 0,42 & 0,87 & 4,35 \\
\hline Myrcia multiflora & 3,00 & 0,22 & 6,25 & 0,92 & 0,04 & 0,09 & 1,23 \\
\hline Myrsine sp. 1 & 6,00 & 0,43 & 6,25 & 0,92 & 0,18 & 0,37 & 1,71 \\
\hline Nectandra sp. & 3,00 & 0,22 & 6,25 & 0,92 & 0,05 & 0,10 & 1,23 \\
\hline Ocotea pulchella & 3,00 & 0,22 & 6,25 & 0,92 & 0,02 & 0,04 & 1,17 \\
\hline Platymiscium floribundum & 25,00 & 1,80 & 37,50 & 5,50 & 1,28 & 2,62 & 9,93 \\
\hline Psidium cattleianum & 140,00 & 10,12 & 75,00 & 11,01 & 3,62 & 7,44 & 28,56 \\
\hline Sapium glandulatum & 3,00 & 0,22 & 6,25 & 0,92 & 0,05 & 0,09 & 1,23 \\
\hline Syagrus romanzoffiana & 38,00 & 2,74 & 43,75 & 6,42 & 1,52 & 3,12 & 12,27 \\
\hline Tabebuia cassinoides & 847,00 & 61,20 & 100,00 & 14,67 & 26,42 & 54,23 & 130,11 \\
\hline Tabebuia umbellata & 3,00 & 0,22 & 6,25 & 0,92 & 0,18 & 0,37 & 1,50 \\
\hline TOTAIS & 1384,00 & 100,00 & 681,25 & 100,00 & 48,72 & 100,00 & 300,00 \\
\hline
\end{tabular}

(Abreviaturas: Abs. = absoluta; Rel. $=$ relativa e $\mathrm{VI}=$ valor de importância $)$

No estrato herbáceo, Hedychium coronarium ocorreu em abundância, seguido de Costus arabicus, Piper spp., Bactris sp., Mollinedia sp. (Monimiaceae), Polypodium spp. e Norantea brasiliensis (Marcgraviaceae), além de outros representantes de Gesneriaceae, Melastomataceae e Mimosaceae. Como epífitas foram abundantes Philodendron spp. e Rhipsalis sp. (Cactaceae) (Figura 5).

No caxetal Atami observa-se a mesma característica das unidades descritas anteriormente, sendo que Tabebuia cassinoides abarca mais de $50 \%$ da densidade e da dominância total (Tabela 5). No entanto, denota-se maior diversidade, comprovada pela ocorrência de 29 espécies arbóreas distribuídas em 21 gêneros de 15 famílias. Embora as alturas das árvores do dossel encontrem-se entre apenas 7 e $12 \mathrm{~m}$, há evidências de um terceiro estrato, baixo, onde destacam-se Alsophila sp. (xaxim) e espécies da família Moraceae.

No estrato superior, além da caxeta, sobressaem Calophyllum brasiliense e Ficus sp., e, no intermediário, Ilex theezans e Ilex dumosa (Figura 6). A ocorrência expressiva de espécies do gênero Ilex pode ser justificada pelo fato de se tratar de uma área de contato entre o ambiente xerófilo e o hidrófilo (sistema de transição restinga seca/úmida) (Andrade, 1967; Leite e Klein, 1990). A ascendência de outras espécies que dividem com a caxeta o espaço do dossel produz alterações na homogeneidade fisionômica típica dos caxetais 


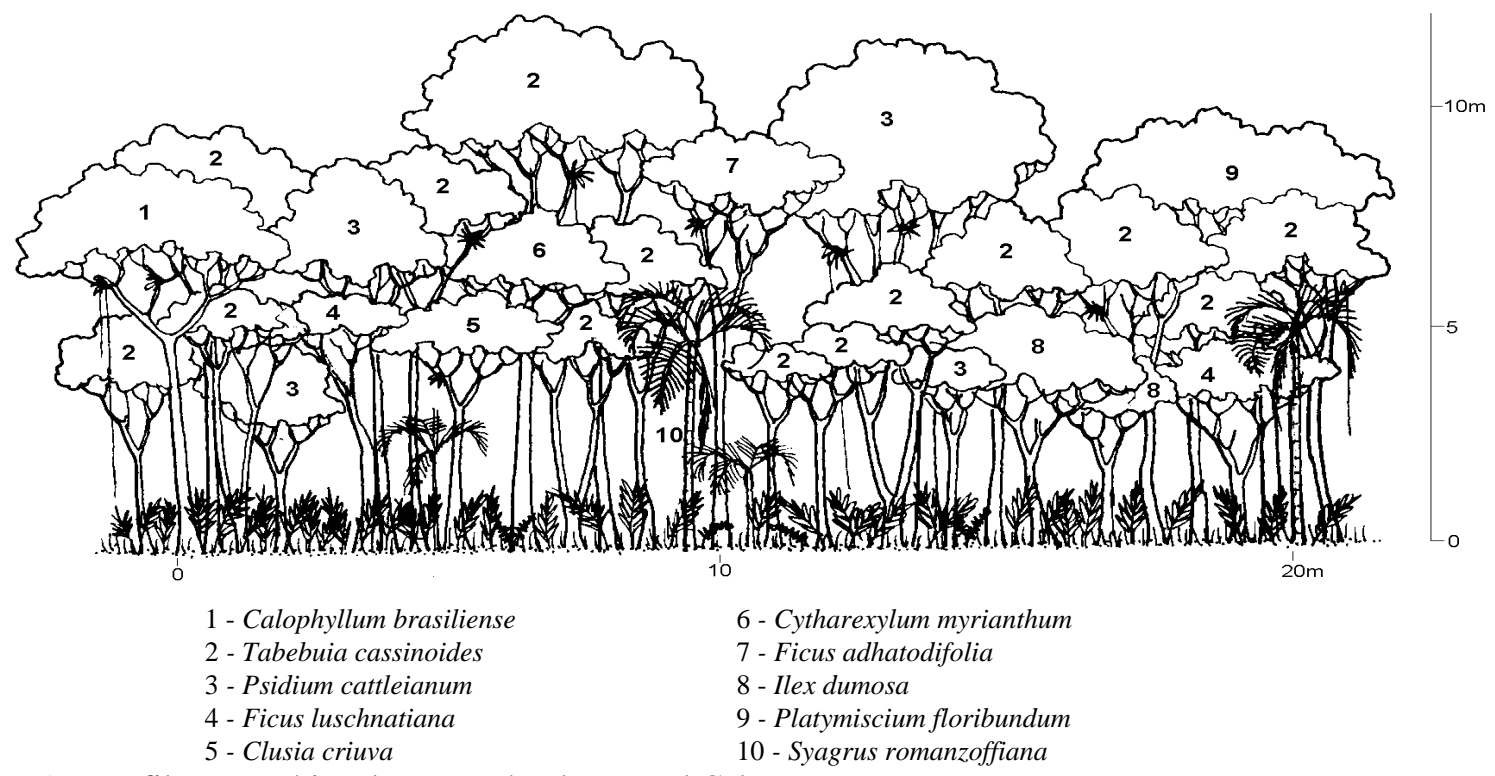

Figura 5: Perfil esquemático de um trecho do caxetal Cabaraquara.

Figure 5: Profile of the Cabaraquara site.

Tabela 5 Valores fitossociológicos do caxetal Atami.

Table 5: Phytossociological results of the Atami site.

\begin{tabular}{|c|c|c|c|c|c|c|c|}
\hline \multirow[b]{2}{*}{ ESPÉCIES } & \multicolumn{2}{|c|}{ DENSIDADE } & \multicolumn{2}{|c|}{ FREQÜÊECIA } & \multicolumn{2}{|c|}{ DOMINÂNCIA } & \multirow[b]{2}{*}{ VI } \\
\hline & $\begin{array}{c}\text { Abs. } \\
\left(\mathrm{N}^{\mathrm{o}} / \mathrm{ha}\right)\end{array}$ & $\begin{array}{l}\text { Rel. } \\
(\%)\end{array}$ & $\begin{array}{l}\text { Abs. } \\
(\%)\end{array}$ & $\begin{array}{l}\text { Rel. } \\
(\%)\end{array}$ & $\begin{array}{c}\text { Abs. } \\
\left(\mathrm{m}^{2} / \mathrm{ha}\right)\end{array}$ & $\begin{array}{l}\text { Rel. } \\
(\%)\end{array}$ & \\
\hline Alchornea triplinervia & 10,00 & 0,49 & 10,00 & 1,15 & 0,07 & 0,19 & 1,83 \\
\hline Alsophila sp. & 25,00 & 1,22 & 30,00 & 3,45 & 0,35 & 0,91 & 5,58 \\
\hline Andira anthelmia & 20,00 & 0,98 & 30,00 & 3,45 & 0,13 & 0,33 & 4,77 \\
\hline Calophyllum brasiliense & 90,00 & 4,39 & 60,00 & 6,90 & 5,54 & 14,36 & 25,65 \\
\hline Calyptranthes lucida & 5,00 & 2,24 & 10,00 & 1,15 & 0,04 & 0,11 & 1,50 \\
\hline Calyptranthes sp. 1 & 5,00 & 0,24 & 10,00 & 1,15 & 0,07 & 0,18 & 1,56 \\
\hline Clusia criuva & 25,00 & 1,22 & 30,00 & 3,45 & 0,24 & 0,63 & 5,31 \\
\hline Coussapoa microcarpa & 5,00 & 0,24 & 10,00 & 1,15 & 0,05 & 0,13 & 1,53 \\
\hline Coussapoa schottii & 5,00 & 0,24 & 10,00 & 1,15 & 0,14 & 0,37 & 1,77 \\
\hline Ficus luschnatiana & 15,00 & 0,73 & 10,00 & 1,15 & 0,37 & 0,96 & 2,85 \\
\hline Ficus sp. & 100,00 & 4,88 & 40,00 & 4,60 & 2,63 & 6,83 & 16,32 \\
\hline Ilex dumosa & 80,00 & 3,90 & 50,00 & 5,75 & 0,98 & 2,55 & 12,21 \\
\hline Ilex theezans & 155,00 & 7,56 & 70,00 & 8,05 & 1,97 & 5,10 & 20,70 \\
\hline Inga edulis & 15,00 & 0,73 & 20,00 & 2,30 & 0,12 & 0,30 & 3,33 \\
\hline Myrcia insularis & 40,00 & 1,95 & 10,00 & 1,15 & 0,61 & 1,59 & 4,68 \\
\hline Myrcia multiflora & 35,00 & 1,71 & 60,00 & 6,90 & 0,30 & 0,77 & 9,39 \\
\hline Myrsine sp. 1 & 55,00 & 2,69 & 50,00 & 5,75 & 0,68 & 1,77 & 10,20 \\
\hline Neea sp. & 10,00 & 0,49 & 10,00 & 1,15 & 0,10 & 0,26 & 1,89 \\
\hline Platymiscium floribundum & 5,00 & 0,24 & 10,00 & 1,15 & 0,08 & 0,20 & 1,59 \\
\hline Psidium cattleianum & 15,00 & 0,73 & 30,00 & 3,45 & 0,08 & 0,20 & 4,38 \\
\hline Syagrus romanzoffiana & 50,00 & 2,44 & 60,00 & 6,90 & 1,06 & 2,73 & 12,06 \\
\hline Symplocos nitidifolia & 5,00 & 0,24 & 10,00 & 1,15 & 0,03 & 0,07 & 1,47 \\
\hline Tabebuia cassinoides & 1095,00 & 53,43 & 100,00 & 11,49 & 19,77 & 51,25 & 116,16 \\
\hline Tapirira guianensis & 15,00 & 0,73 & 20,00 & 2,30 & 0,11 & 0,28 & 3,30 \\
\hline Tibouchina multiceps & 65,00 & 3,18 & 40,00 & 4,60 & 0,48 & 1,23 & 9,00 \\
\hline Moraceae 1 & 5,00 & 0,24 & 10,00 & 1,15 & 0,04 & 0,11 & 1,50 \\
\hline Moraceae 2 & 15,00 & 0,73 & 20,00 & 2,30 & 0,15 & 0,40 & 3,42 \\
\hline Moraceae 3 & 80,00 & 3,90 & 40,00 & 4,60 & 2,32 & 6,01 & 14,52 \\
\hline Moraceae 4 & 5,00 & 0,24 & 10,00 & 1,15 & 0,07 & 0,18 & 1,56 \\
\hline TOTAIS & 2050,00 & 100,00 & 870,00 & 100,00 & 38,58 & 100,00 & 300,00 \\
\hline
\end{tabular}

(Abreviaturas: Abs. $=$ absoluta; Rel. $=$ relativa e VI = valor de importância $)$ 


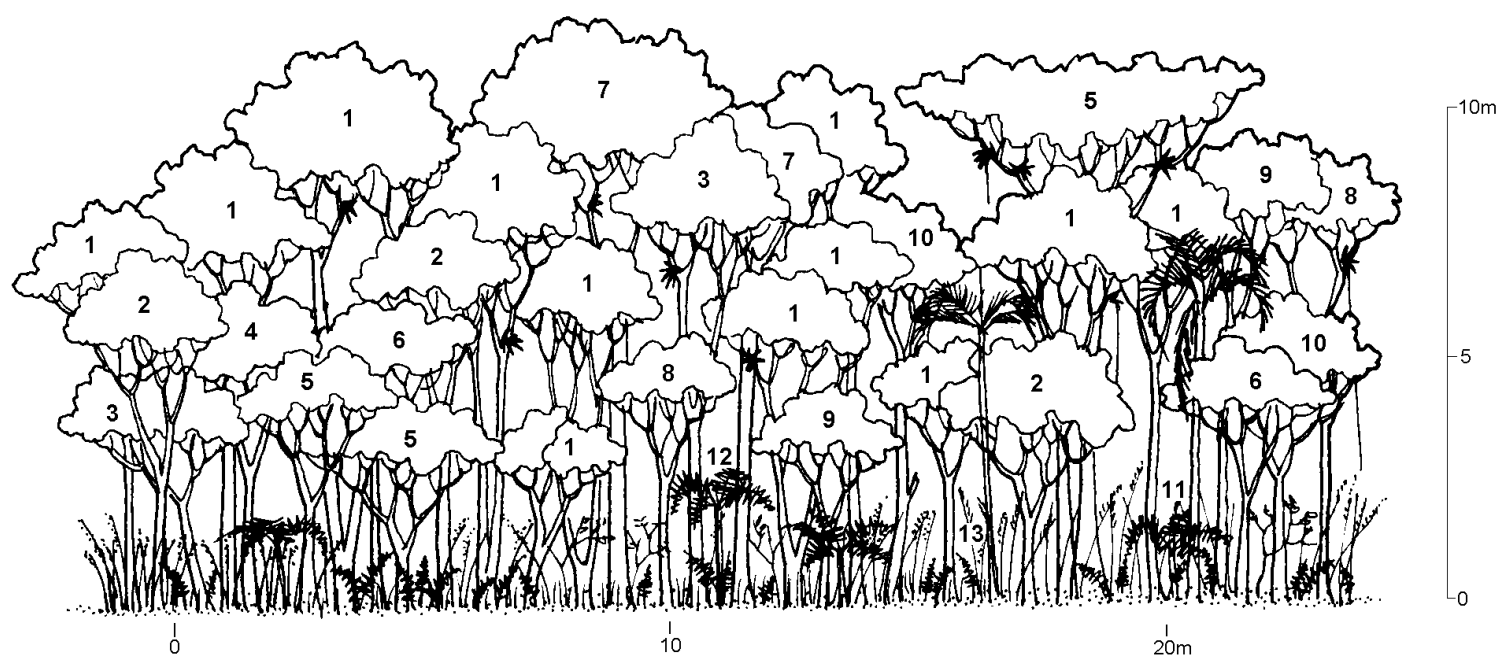

1- Tabebuia cassinoides

2 - Ilex theezans

3 - Myrsine sp.

4 - Clusia criuva

5 - Ficus sp.
6 - Moraceae 3

7 - Calophyllum brasiliense

8 - Myrcia multiflora

9 - Tibouchina multiceps

10 - Ilex dumosa
11 - Syagrus romanzoffiana

12 - Alsophila sp.

13 - Euterpe edulis

Figura 6: Perfil esquemático de um trecho do caxetal Atami.

Figure 6: Profile of the Atami site.

No estrato herbáceo predomina Fuirena umbellata (Cyperaceae), junto a outras espécies menos abundantes, como Blechnum sp. (Cyatheaceae), Polypodium spp., Piper spp., Smilax sp., Costus arabicus e representantes de Melastomataceae. Como epífitas destacam-se espécies das famílias Gesneriaceae e Cactaceae.

No caxetal Guaratuba 1 foram registradas 26 espécies arbóreas pertencentes a 14 famílias. As famílias Myrtaceae, com 6 espécies (23\% do total), e Myrsinaceae, com 4 $(15 \%)$, foram as mais representativas. A distribuição das espécies nas famílias restantes manteve-se entre 1 e 3 apenas. Em função da elevada densidade de caxeta destacou-se a família Bignoniaceae, ainda que representada apenas pela mesma e pelo ipê-do-brejo (Tabebuia umbellata) (Tabela 6).
As alturas máximas dessa unidade situaram-se entre 8 e $12 \mathrm{~m}$, com eventuais emergentes que não ultrapassaram $16 \mathrm{~m}$. $\mathrm{O}$ estrato médio esteve compreendido numa faixa de 5 a $8 \mathrm{~m}$, e o inferior, entre 2 e $5 \mathrm{~m}$. Estes padrões de altura tendem a ser um pouco menores em áreas recentemente exploradas ou de densidade mais baixa.

Nessa unidade também fica evidente o domínio de Tabebuia cassinoides, tendo ainda destacada importância, pelas suas densidades e por ocuparem preferentemente o dossel, Syagrus romanzoffiana e Tabebuia umbellata. Típicas do sub-bosque são Marlierea tomentosa, Myrcia multiflora, Eugenia umbelliflora e Inga edulis, além de exemplares em regeneração de Euterpe edulis e Calophyllum brasiliense, entre outras (Figura 7). 
Tabela 6: Valores fitossociológicos do caxetal Guaratuba 1.

Table 6: $\quad$ Phytossociological results of the Guaratuba 1 site.

\begin{tabular}{|c|c|c|c|c|c|c|c|}
\hline \multirow[b]{2}{*}{ ESPÉCIES } & \multicolumn{2}{|c|}{ DENSIDADE } & \multicolumn{2}{|c|}{ FREQÜÊNCIA } & \multicolumn{2}{|c|}{ DOMINÂNCIA } & \multirow[b]{2}{*}{ VI } \\
\hline & $\begin{array}{c}\text { Abs. } \\
\left(\mathrm{N}^{\mathrm{o}} / \mathrm{ha}\right)\end{array}$ & $\begin{array}{l}\text { Rel. } \\
(\%)\end{array}$ & $\begin{array}{c}\text { Abs. } \\
(\%)\end{array}$ & $\begin{array}{l}\text { Rel. } \\
(\%)\end{array}$ & $\begin{array}{c}\text { Abs. } \\
\left(\mathrm{m}^{2} / \mathrm{ha}\right)\end{array}$ & $\begin{array}{l}\text { Rel. } \\
(\%)\end{array}$ & \\
\hline Andira anthelmia & 33,33 & 2,50 & 20,00 & 4,05 & 0,51 & 1,85 & 8,40 \\
\hline Calophyllum brasiliense & 20,00 & 1,50 & 13,33 & 2,71 & 0,42 & 1,52 & 5,73 \\
\hline Calycorectes sp. 1 & 26,67 & 2,00 & 20,00 & 4,05 & 0,34 & 1,24 & 7,29 \\
\hline Eugenia umbelliflora & 13,33 & 1,00 & 13,33 & 2,71 & 0,14 & 0,51 & 4,22 \\
\hline Euterpe edulis & 6,67 & 0,50 & 6,67 & 1,35 & 0,05 & 0,18 & 2,03 \\
\hline Gomidesia palustris & 13,33 & 1,00 & 6,67 & 1,35 & 0,21 & 0,76 & 3,11 \\
\hline Guapira opposita & 6,67 & 0,50 & 6,67 & 1,35 & 0,05 & 0,19 & 2,04 \\
\hline Ilex dumosa & 26,67 & 2,00 & 20,00 & 4,05 & 0,28 & 1,02 & 7,07 \\
\hline Inga edulis & 46,67 & 3,50 & 33,33 & 6,75 & 0,90 & 3,27 & 13,52 \\
\hline Inga marginata & 6,67 & 0,50 & 6,67 & 1,35 & 0,09 & 0,34 & 2,19 \\
\hline Marlierea tomentosa & 20,00 & 1,50 & 20,00 & 4,05 & 0,18 & 0,64 & 6,19 \\
\hline Matayba guianensis & 6,67 & 0,50 & 6,67 & 1,35 & 0,06 & 0,23 & 2,08 \\
\hline Miconia sp. & 6,67 & 0,50 & 6,67 & 1,35 & 0,09 & 0,33 & 2,18 \\
\hline Myrcia multiflora & 13,33 & 1,00 & 6,67 & 1,35 & 0,12 & 0,43 & 2,78 \\
\hline Myrsine parvifolia & 6,67 & 0,50 & 6,67 & 1,35 & 0,11 & 0,40 & 2,25 \\
\hline Myrsine umbellata & 13,33 & 1,00 & 13,33 & 2,71 & 0,24 & 0,87 & 4,58 \\
\hline Myrsine sp. 1 & 6,67 & 0,50 & 6,67 & 1,35 & 0,06 & 0,23 & 2,08 \\
\hline Myrsine sp. 2 & 6,67 & 0,50 & 6,67 & 1,35 & 0,13 & 0,46 & 2,31 \\
\hline Psidium cattleianum & 13,33 & 1,00 & 6,67 & 1,35 & 0,32 & 1,16 & 3,51 \\
\hline Rollinia rugulosa & 6,67 & 0,50 & 6,67 & 1,35 & 0,06 & 0,21 & 2,06 \\
\hline Sapium glandulatum & 13,33 & 1,00 & 13,33 & 2,71 & 0,34 & 1,22 & 4,93 \\
\hline Syagrus romanzoffiana & 166,67 & 12,50 & 80,00 & 16,22 & 6,10 & 22,18 & 50,90 \\
\hline Tabebuia cassinoides & 726,67 & 54,50 & 100,00 & 20,28 & 13,97 & 50,79 & 125,57 \\
\hline Tabebuia umbellata & 60,00 & 4,49 & 33,33 & 6,75 & 1,93 & 7,02 & 18,26 \\
\hline Tibouchina multiceps & 6,67 & 0,50 & 6,67 & 1,35 & 0,05 & 0,19 & 2,04 \\
\hline Trichipteris atrovirens & 60,00 & 4,49 & 26,67 & 5,41 & 0,76 & 2,76 & 12,66 \\
\hline TOTAL & 1333,36 & 100,00 & 493,36 & 100,00 & 27,51 & 100,00 & 300,00 \\
\hline
\end{tabular}

(Abreviaturas: Abs. = absoluta; Rel. $=$ relativa e VI = valor de importância $)$

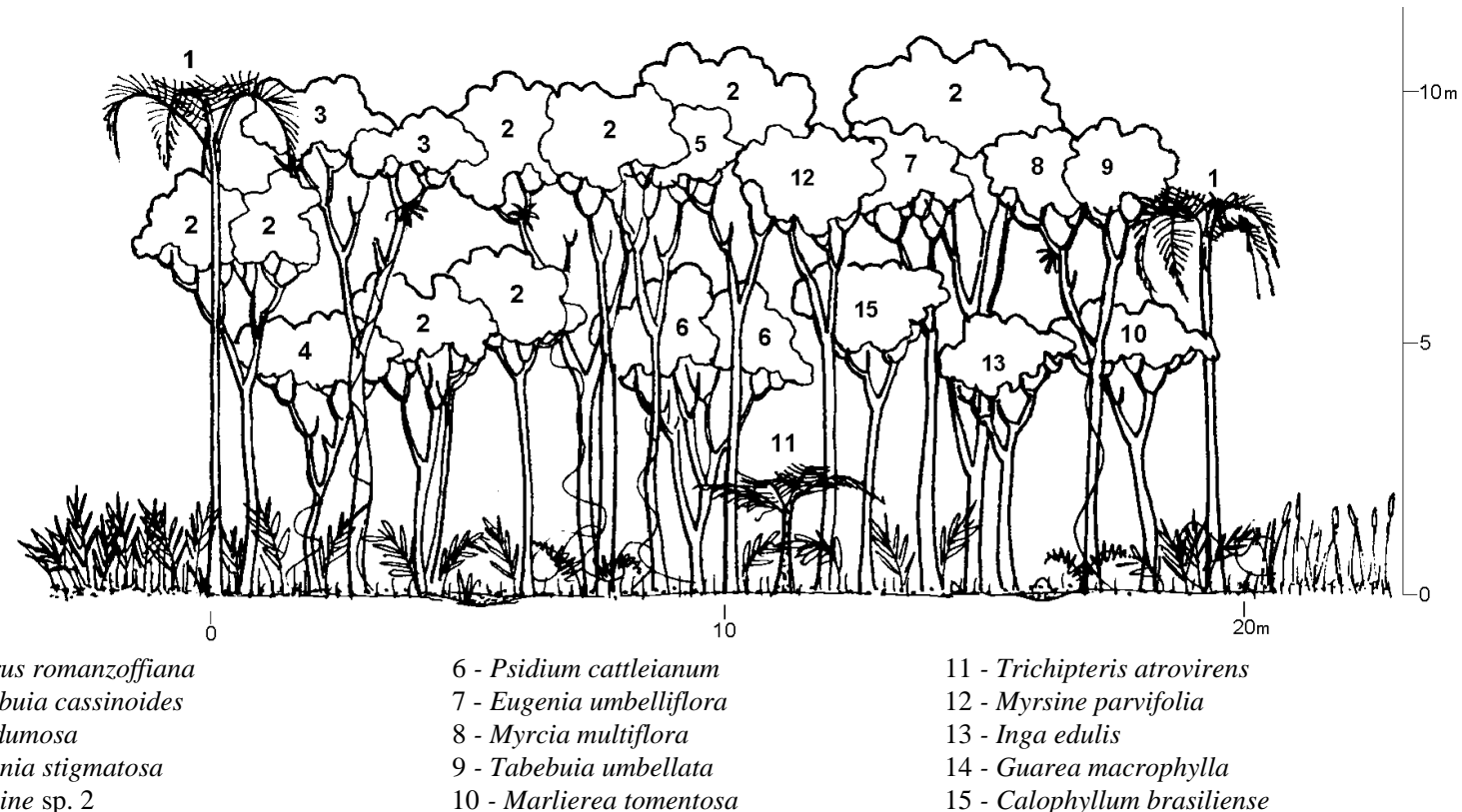

Figura 7: Perfil esquemático de um trecho do caxetal Guaratuba 1

Figure 7: Profile of the Guaratuba 1 site. 
Trata-se de um ambiente rico em Bromeliaceae, principalmente epífitas, além de Araceae, Orchidaceae, Piperaceae, Zingiberaceae e Costaceae, sendo as duas últimas famílias representadas por Hedychium coronarium e Costus arabicus respectivamente, as herbáceas mais típicas dessa unidade.

De todos os caxetais amostrados, o de Alexandra-Matinhos é o que apresenta maior dominância, principalmente devido à ocorrência de indivíduos bem desenvolvidos de Calophyllum brasiliense, ainda que em número bem inferior a Tabebuia cassinoides (Tabela 7). Tal fato é determinante para projetar Calophyllum brasiliense no mesmo patamar de importância de Tabebuia cassinoides nessa área. Diferentemente dos caxetais anteriores, em que o maior número de indivíduos encontrava-se no estrato superior, nesse caso, em função da ocorrência expressiva de Tabebuia cassinoides e de Marlierea tomentosa, é o estrato intermediário que lidera. Isso não ocorre com a dominância, pois os indivíduos de maiores diâmetros também apresentam as maiores alturas.

A diversidade de espécies e de formas de vida é visivelmente maior do que nos casos anteriores, sendo a distribuição de indivíduos por espécie mais homogênea, ou seja, a dominância não se encontrava concentrada em uma ou poucas espécies. Isso é particularmente verdadeiro para o sub-bosque herbáceo-arbustivo e para as arvoretas da regeneração natural. A caxeta ocupa, preferencialmente, o estrato médio, havendo perdido o espaço do dossel para espécies de maior porte como Calophyllum brasiliense e Ficus spp., que produzem alterações contrastantes na fisionomia homogênea dos casos anteriores.

Dos ambientes até o momento descritos, esse é o de maior complexidade florística e estrutural, manifesta pelos três estratos arbóreos distintos, onde o superior situa-se entre 14 e $18 \mathrm{~m}$, o intermediário entre 7 e $14 \mathrm{~m}$ e o inferior abaixo de $7 \mathrm{~m}$, pela ocorrência de 36 espécies árbóreas e pela abundância de epífitas. O sub-bosque é denso, e as espécies mais evidentes são Costus arabicus, Calathea sp., Piper spp., Polypodium spp., Blechnum sp., Nematanthus fissus (Gesneriaceae), Begonia spp., Bactris sp., Philodendron spp. e Anthurium scandens (Araceae) são as epífitas mais representativas (Figura 8).

É conveniente mencionar que foi observado nos caxetais Atami e AlexandraMatinhos a ocorrência de caxeta-vermelha, que morfologicamente apresenta diferenças em relação à caxeta comum, também chamada de caxeta-branca. Além da casca externa (ritidoma) ser mais fissurada, a casca interna não tem a coloração esbranquiçada característica e sim avermelhada, e a sua madeira é conhecida pelos mateiros como sendo de melhor qualidade. Esses indivíduos foram inicialmente incluídos em outra espécie ou variedade, mas, não havendo embasamento taxonômico, os números que os representam foram agrupados como em Tabebuia cassinoides. Em Atami, registrou-se 65 ind./ha (3,18\% do total) de caxeta-vermelha, $50 \%$ de frequiência absoluta $(5,43 \%$ do total), 1,07 $\mathrm{m}^{2} /$ ha $(2,78 \%$ do total) e valor de importância de $11,40 \%$. No caxetal Alexandra-Matinhos, dos valores tabulados para Tabebuia cassinoides, são considerados como caxetavermelha apenas 5 ind./ha $(0,30 \%$ do total), $10 \%$ de freqüência absoluta $(0,93 \%), 0,08$ $\mathrm{m}^{2} /$ ha $(0,16 \%$ do total $)$ e valor de importância de $1,38 \%$.

Mesmo não tendo sido amostrada por completo a florística do caxetal Guaratuba 2, foram encontradas 78 espécies, pertencentes a 31 famílias botânicas. Myrtaceae é a mais expressiva, com 21 espécies, perfazendo $27 \%$ do total amostrado. Seguem-se Lauraceae, com 8, Euphorbiaceae, com 6, e Clusiaceae e Bignoniaceae, com 3 espécies.

O dossel dessa formação situa-se entre 20 e $24 \mathrm{~m}$ de altura, destacando-se representantes das famílias Clusiaceae, Anacardiaceae, Lauraceae, Bombacacee, Myrtaceae, Moraceae e Sapindaceae. No estrato intermediário, entre 14 e $20 \mathrm{~m}$ de altura, sobressaem-se as famílias Bignoniaceae, Arecaceae, Fabaceae, Euphorbiaceae, Lauraceae, Myrtaceae, Meliaceae, Moraceae, Myrsinaceae, 
Clethraceae e Araliaceae. No estrato arbóreo inferior, situado abaixo de $14 \mathrm{~m}$, observa-se uma maior densidade de Rubiaceae, Arecaceae, Myrtaceae, Celastraceae,
Malpighiaceae, Sapindaceae, Sapotaceae, Thymelaeaceae e pteridófitas arborescentes (Figura 9).

Tabela 7: Valores fitossociológicos do caxetal Alexandra-Matinhos.

Table 7: Phytossociological results of the Alexandra-Matinhos site.

\begin{tabular}{|c|c|c|c|c|c|c|c|}
\hline \multirow[b]{2}{*}{ ESPÉCIES } & \multicolumn{2}{|c|}{ DENSIDADE } & \multicolumn{2}{|c|}{ FREQÜÊENCIA } & \multicolumn{2}{|c|}{ DOMINÂNCIA } & \multirow[b]{2}{*}{ VI } \\
\hline & $\begin{array}{c}\text { Abs. } \\
\left(\mathrm{N}^{\mathrm{o}} / \mathrm{ha}\right)\end{array}$ & $\begin{array}{l}\text { Rel. } \\
(\%)\end{array}$ & $\begin{array}{l}\text { Abs. } \\
(\%)\end{array}$ & $\begin{array}{l}\text { Rel. } \\
(\%)\end{array}$ & $\begin{array}{c}\text { Abs. } \\
\left(\mathrm{m}^{2} / \mathrm{ha}\right)\end{array}$ & $\begin{array}{l}\text { Rel. } \\
(\%)\end{array}$ & \\
\hline Alchornea sidifolia & 45,00 & 2,67 & 50,00 & 4,72 & 1,19 & 2,39 & 9,78 \\
\hline Alchornea triplinervia & 10,00 & 0,59 & 10,00 & 0,94 & 0,13 & 0,26 & 1,80 \\
\hline Alsophila $\mathrm{sp}$. & 20,00 & 1,19 & 20,00 & 1,89 & 0,36 & 0,72 & 3,87 \\
\hline Andira anthelmia & 5,00 & 0,30 & 10,00 & 0,94 & 0,03 & 0,06 & 1,29 \\
\hline Calophyllum brasiliense & 145,00 & 8,60 & 80,00 & 7,55 & 20,66 & 41,52 & 57,66 \\
\hline Calyptranthes lucida & 25,00 & 1,48 & 30,00 & 2,83 & 0,24 & 0,48 & 4,80 \\
\hline Calyptranthes sp.1 & 20,00 & 1,19 & 30,00 & 2,83 & 0,23 & 0,46 & 4,47 \\
\hline Calyptranthes sp. 2 & 15,00 & 0,89 & 30,00 & 2,83 & 0,11 & 0,22 & 3,93 \\
\hline Cecropia pachystachya & 30,00 & 1,78 & 20,00 & 1,89 & 0,51 & 1,03 & 4,71 \\
\hline Cytharexylum myrianthum & 5,00 & 0,30 & 10,00 & 0,94 & 0,08 & 0,16 & 1,41 \\
\hline Clusia criuva & 15,00 & 0,89 & 10,00 & 0,94 & 0,12 & 0,24 & 2,07 \\
\hline Ficus adhatodifolia & 25,00 & 1,48 & 40,00 & 3,78 & 0,72 & 1,45 & 6,69 \\
\hline Ficus luschnathiana & 35,00 & 2,08 & 60,00 & 5,66 & 1,02 & 2,05 & 9,78 \\
\hline Guarea macrophylla & 5,00 & 0,30 & 10,00 & 0,94 & 0,03 & 0,06 & 1,29 \\
\hline Hedyosmum brasiliense & 25,00 & 1,48 & 40,00 & 3,78 & 0,19 & 0,38 & 5,64 \\
\hline Ilex dumosa & 5,00 & 0,30 & 10,00 & 0,94 & 0,12 & 0,24 & 1,47 \\
\hline Inga edulis & 65,00 & 3,85 & 40,00 & 3,78 & 0,90 & 1,81 & 9,42 \\
\hline Marlierea obscura & 35,00 & 2,08 & 40,00 & 3,78 & 0,52 & 1,05 & 6,90 \\
\hline Marlierea tomentosa & 110,00 & 6,52 & 60,00 & 5,66 & 1,00 & 2,01 & 14,19 \\
\hline Matayba guianensis & 5,00 & 0,30 & 10,00 & 0,94 & 0,03 & 0,06 & 1,29 \\
\hline Myrcia insularis & 5,00 & 0,30 & 10,00 & 0,94 & 0,03 & 0,06 & 1,29 \\
\hline Myrcia multiflora & 25,00 & 1,48 & 40,00 & 3,77 & 0,33 & 0,67 & 5,91 \\
\hline Myrsine sp. 1 & 35,00 & 2,08 & 50,00 & 4,72 & 0,54 & 1,09 & 7,89 \\
\hline Ocotea sp. & 5,00 & 0,30 & 10,00 & 0,94 & 0,04 & 0,08 & 1,32 \\
\hline Pera glabrata & 10,00 & 0,59 & 20,00 & 1,89 & 0,25 & 0,50 & 2,97 \\
\hline Platymiscium floribundum & 15,00 & 0,89 & 30,00 & 2,83 & 0,77 & 1,55 & 5,28 \\
\hline Pseudobombax grandiflorum & 5,00 & 0,30 & 10,00 & 0,94 & 0,27 & 0,54 & 1,77 \\
\hline Psidium cattleianum & 15,00 & 0,89 & 20,00 & 1,89 & 0,10 & 0,20 & 2,97 \\
\hline Syagrus romanzoffiana & 65,00 & 3,85 & 70,00 & 6,60 & 2,20 & 4,42 & 14,88 \\
\hline Tabebuia cassinoides & 805,00 & 47,79 & 100,00 & 9,43 & 15,77 & 31,69 & 88,89 \\
\hline Tabebuia umbellata & 10,00 & 0,59 & 20,00 & 1,89 & 0,26 & 0,53 & 3,00 \\
\hline Tapirira guianensis & 15,00 & 0,89 & 20,00 & 1,89 & 0,29 & 0,58 & 3,36 \\
\hline Tibouchina multiceps & 10,00 & 0,59 & 20,00 & 1,89 & 0,07 & 0,14 & 2,61 \\
\hline Weinmannia pauliniaefolia & 10,00 & 0,59 & 10,00 & 0,94 & 0,14 & 0,28 & 1,80 \\
\hline Moraceae 1 & 5,00 & 0,30 & 10,00 & 0,94 & 0,30 & 0,60 & 1,83 \\
\hline Moraceae 2 & 5,00 & 0,30 & 10,00 & 0,94 & 0,21 & 0,42 & 1,65 \\
\hline TOTAIS & 1685,00 & 100,00 & 1060,00 & 100,00 & 49,71 & 100,00 & 300,00 \\
\hline
\end{tabular}

(Abreviaturas: Abs. = absoluta; Rel. $=$ relativa e $\mathrm{VI}=$ valor de importância $)$

Ao analisar a densidade das espécies arbóreas, observa-se a ocorrência menos expressiva de Tabebuia cassinoides $(9,2 \%)$, mostrando equilíbrio com a de outras espécies, principalmente Calophyllum brasiliense (8,9\%), Syagrus romanzoffiana $(8,7 \%)$, Pera glabrata $(4,3 \%)$ e Tapirira guianensis $(3,6 \%)$. Essa distribuição denota diferenças significativas, estruturais, florísticas e fisionômicas, em relação aos caxetais com predomínio de Tabebuia cassinoides (Tabela 8). Todas essas espécies citadas, juntamente com Alchornea triplinervia e Andira anthelmia, ocorreram em pelo menos $40 \%$ das parcelas alocadas. Observou-se também um grande número de espécies com freqüências bastante baixas, indicando, dentre outras causas, estratégias de sobrevivência e a entrada de novos taxa. 


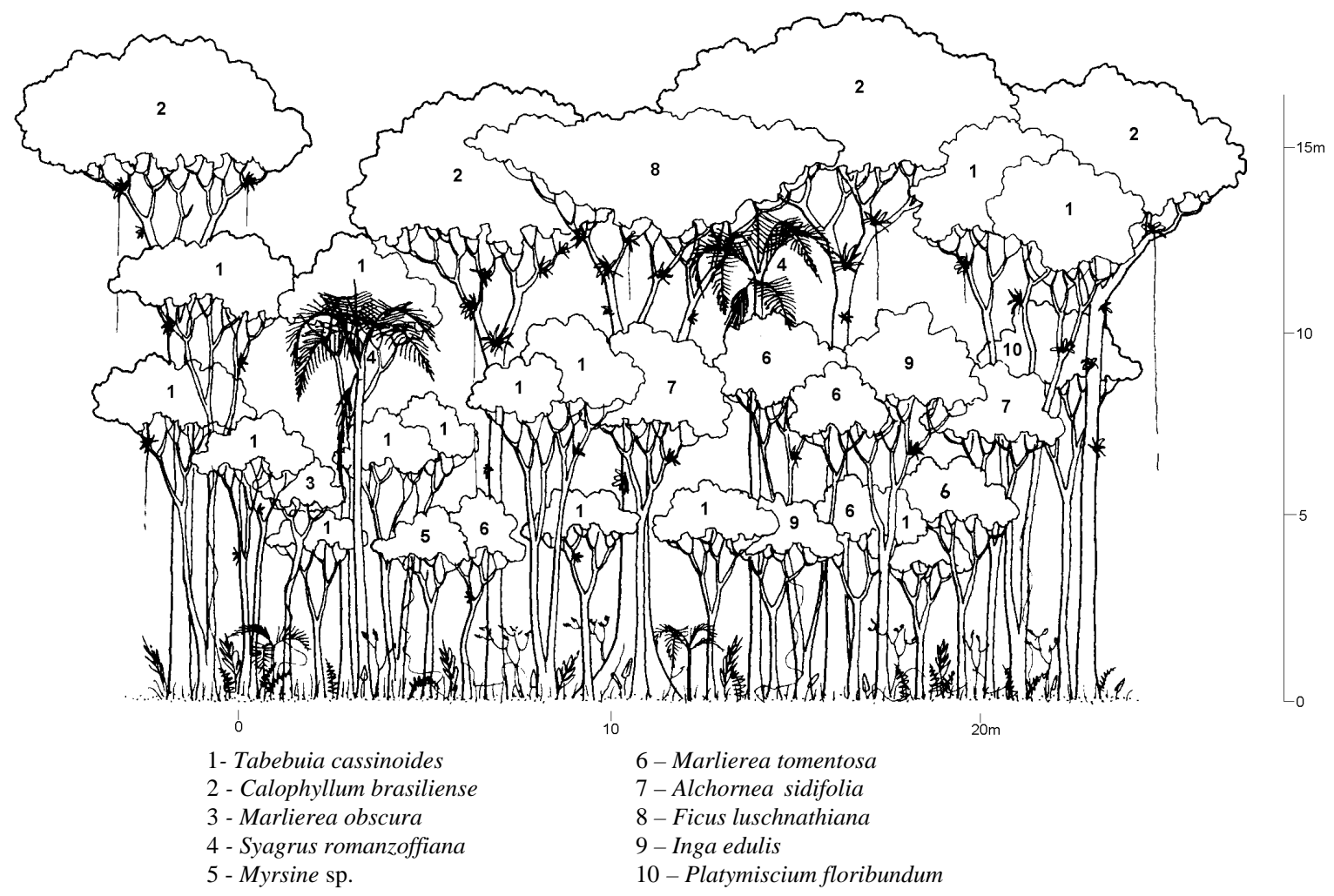

Figura 8: Perfil esquemático de um trecho do caxetal Alexandra-Matinhos.

Figure 8: Profile of the Alexandra-Matinhos site.

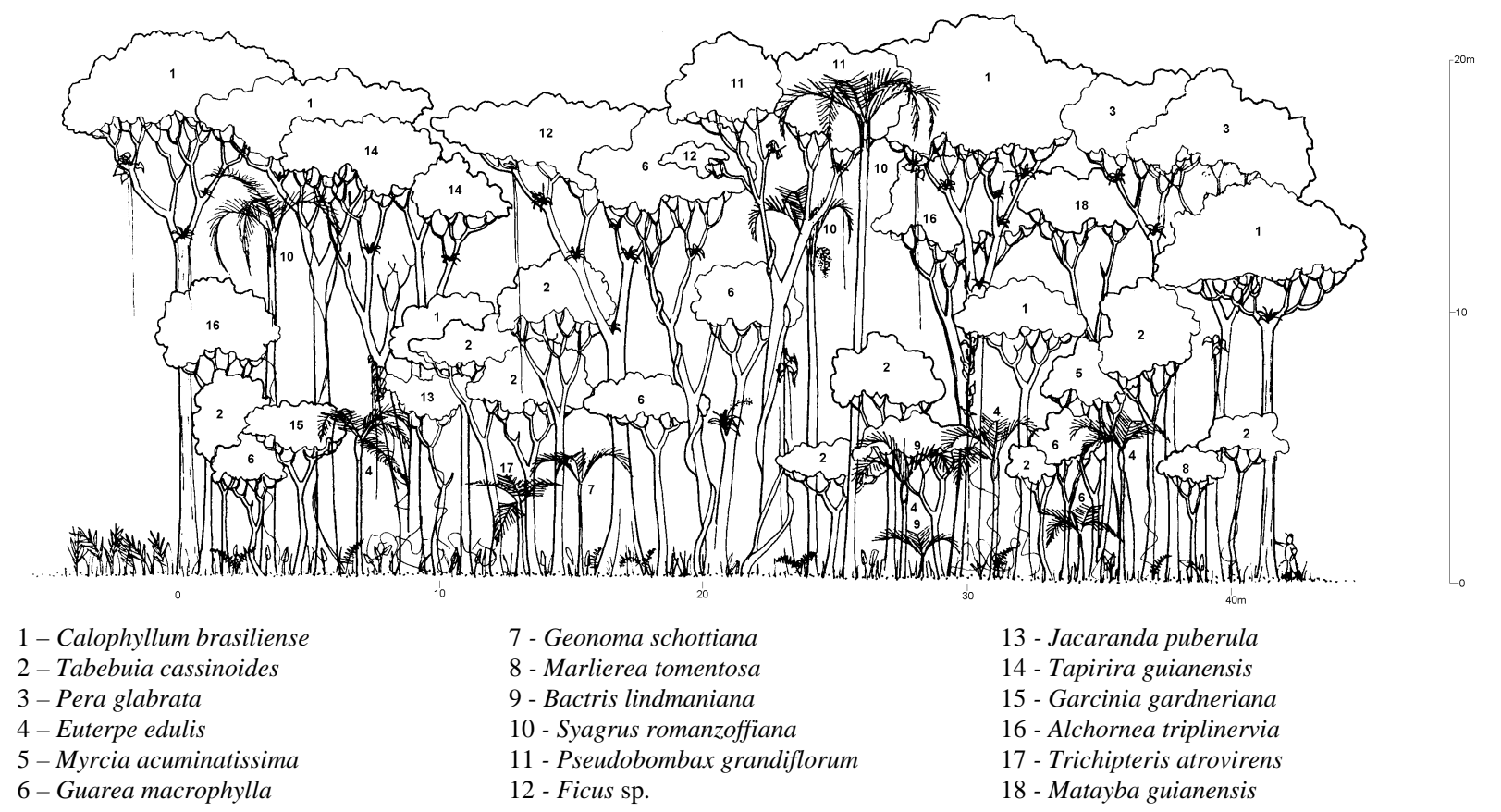

Figura 9: Perfil esquemático de um trecho do caxetal Gauratuba 2

Figure 9: Profile of the Guaratuba 2 site 
Tabela 8: Valores fitossociológicos do caxetal Guaratuba 2.

Table 8: $\quad$ Phytossociological results of the Guaratuba 2 site.

\begin{tabular}{|c|c|c|c|c|c|c|c|}
\hline \multirow{2}{*}{ ESPÉCIES } & \multicolumn{2}{|c|}{ DENSIDADE } & \multicolumn{2}{|c|}{ FREQÜÊNCIA } & \multicolumn{2}{|c|}{ DOMINÂNCIA } & \multirow[b]{2}{*}{ VI } \\
\hline & Abs. (N/ha) & Rel. (\%) & Abs. (\%) & Rel. (\%) & Abs. $\left(\mathrm{m}^{2} / \mathrm{ha}\right)$ & Rel. (\%) & \\
\hline Aegiphila sellowiana & 5,00 & 0,46 & 5,00 & 0,42 & 0,06 & 0,15 & 1,03 \\
\hline Alchornea triplinervia & 35,00 & 3,23 & 40,00 & 3,39 & 1,92 & 4,79 & 11,41 \\
\hline Amaioua guianensis & 10,00 & 0,92 & 10,00 & 0,85 & 0,10 & 0,25 & 2,02 \\
\hline Andira anthelmia & 30,00 & 2,76 & 40,00 & 3,39 & 0,51 & 1,27 & 7,42 \\
\hline Aparisthmium cordatum & 2,50 & 0,23 & 5,00 & 0,42 & 0,14 & 0,35 & 1,00 \\
\hline Byrsonima niedenzuiana & 7,50 & 0,69 & 15,00 & 1,27 & 0,13 & 0,32 & 2,28 \\
\hline Cabralea canjerana & 2,50 & 0,23 & 5,00 & 0,42 & 0,13 & 0,32 & 0,97 \\
\hline Calophyllum brasiliense & 97,50 & 8,99 & 75,00 & 6,36 & 9,91 & 24,74 & 40,09 \\
\hline Calycorectes sp. 1 & 7,50 & 0,69 & 5,00 & 0,42 & 0,22 & 0,55 & 1,66 \\
\hline Calycorectes sp. 2 & 12,50 & 1,15 & 20,00 & 1,69 & 0,30 & 0,75 & 3,59 \\
\hline Calycorectes sp. 3 & 2,50 & 0,23 & 5,00 & 0,42 & 0,06 & 0,15 & 0,80 \\
\hline Calyptranthes conccina & 12,50 & 1,15 & 20,00 & 1,69 & 0,65 & 1,62 & 4,46 \\
\hline Calyptranthes lanceolata & 2,50 & 0,23 & 5,00 & 0,42 & 0,06 & 0,15 & 0,80 \\
\hline Calyptranthes sp. 2 & 5,00 & 0,46 & 5,00 & 0,42 & 0,06 & 0,15 & 1,03 \\
\hline Clethra scabra & 2,50 & 0,23 & 5,00 & 0,42 & 0,06 & 0,15 & 0,80 \\
\hline Clusia criuva & 17,50 & 1,61 & 25,00 & 2,12 & 0,52 & 1,30 & 5,03 \\
\hline Cupania oblongifolia & 5,00 & 0,46 & 10,00 & 0,85 & 0,26 & 0,65 & 1,96 \\
\hline Eugenia cereja & 5,00 & 0,46 & 5,00 & 0,42 & 0,05 & 0,13 & 1,01 \\
\hline Eugenia obovata & 7,50 & 0,69 & 10,00 & 0,85 & 0,06 & 0,15 & 1,69 \\
\hline Eugenia sulcata & 15,00 & 1,38 & 15,00 & 1,27 & 0,17 & 0,42 & 3,07 \\
\hline Eugenia umbelliflora & 5,00 & 0,46 & 10,00 & 0,85 & 0,05 & 0,13 & 1,44 \\
\hline Ficus lushnathiana & 7,50 & 0,69 & 15,00 & 1,27 & 0,55 & 1,37 & 3,33 \\
\hline Ficus sp. & 20,00 & 1,84 & 25,00 & 2,12 & 0,43 & 1,07 & 5,03 \\
\hline Geonoma schottiana & 2,50 & 0,23 & 5,00 & 0,42 & 0,44 & 1,10 & 1,75 \\
\hline Gomidesia palustris & 2,50 & 0,23 & 5,00 & 0,42 & 0,02 & 0,05 & 0,70 \\
\hline Guapira opposita & 12,50 & 1,15 & 5,00 & 0,42 & 0,32 & 0,80 & 2,37 \\
\hline Guarea macrophylla & 15,00 & 1,38 & 25,00 & 2,12 & 0,59 & 1,47 & 4,97 \\
\hline Hyeronima alchorneoides & 7,50 & 0,69 & 10,00 & 0,85 & 0,12 & 0,30 & 1,84 \\
\hline Ilex psammophila & 2,50 & 0,23 & 5,00 & 0,42 & 0,12 & 0,30 & 0,95 \\
\hline Inga edulis & 15,00 & 1,38 & 25,00 & 2,12 & 0,22 & 0,55 & 4,05 \\
\hline Inga sessilis & 2,50 & 0,23 & 5,00 & 0,42 & 0,04 & 0,10 & 0,75 \\
\hline Jacaranda puberula & 25,00 & 2,30 & 30,00 & 2,54 & 0,54 & 1,35 & 6,19 \\
\hline Marlierea eugeniopsoides & 10,00 & 0,92 & 10,00 & 0,85 & 0,11 & 0,27 & 2,04 \\
\hline Marlierea parviflora & 17,50 & 1,61 & 20,00 & 1,69 & 0,25 & 0,62 & 3,92 \\
\hline Marlierea tomentosa & 32,50 & 2,80 & 15,00 & 1,27 & 0,47 & 1,17 & 5,24 \\
\hline Marlierea sp. & 2,50 & 0,23 & 5,00 & 0,42 & 0,03 & 0,07 & 0,72 \\
\hline Matayba guianensis & 10,00 & 0,92 & 15,00 & 1,27 & 0,60 & 1,50 & 3,69 \\
\hline Maytenus alaternoides & 7,50 & 0,69 & 10,00 & 0,85 & 0,14 & 0,40 & 1,94 \\
\hline Mollinedia uleana & 5,00 & 0,46 & 10,00 & 0,85 & 0,13 & 0,32 & 1,63 \\
\hline Myrcia acuminatissima & 20,00 & 1,84 & 30,00 & 2,54 & 0,20 & 0,57 & 4,95 \\
\hline Myrcia multiflora & 7,50 & 0,69 & 10,00 & 0,85 & 0,13 & 0,32 & 1,86 \\
\hline Myrcia pubipetala & 10,00 & 0,92 & 15,00 & 1,27 & 0,23 & 0,57 & 2,76 \\
\hline Myrsine parvifolia & 5,00 & 0,46 & 10,00 & 0,85 & 0,06 & 0,15 & 1,46 \\
\hline Myrsine umbellata & 17,50 & 1,61 & 25,00 & 2,12 & 0,28 & 0,70 & 4,43 \\
\hline Nectandra megapotamica & 2,50 & 0,23 & 5,00 & 0,42 & 0,10 & 0,25 & 0,90 \\
\hline Nectandra rigida & 12,50 & 1,15 & 15,00 & 1,27 & 0,59 & 1,47 & 3,89 \\
\hline Nectandra sp. & 2,50 & 0,23 & 5,00 & 0,42 & 0,01 & 0,05 & 0,70 \\
\hline Ocotea aciphylla & 5,00 & 0,46 & 10,00 & 0,85 & 0,04 & 0,10 & 1,41 \\
\hline Ocotea pulchella & 27,50 & 2,53 & 20,00 & 1,69 & 1,44 & 3,59 & 7,81 \\
\hline Ocotea $\mathrm{sp}$ & 2,50 & 0,23 & 5,00 & 0,42 & 0,10 & 0,25 & 0,90 \\
\hline Pera glabrata & 47,50 & 4,38 & 55,00 & 4,66 & 1,37 & 3,42 & 12,46 \\
\hline Pera sp. & 7,50 & 0,69 & 15,00 & 1,27 & 0,27 & 0,67 & 2,63 \\
\hline Posoqueria latifolia & 15,00 & 1,38 & 20,00 & 1,69 & 0,21 & 0,52 & 3,59 \\
\hline Pouteria caimito & 10,00 & 0,92 & 15,00 & 1,27 & 0,36 & 0,90 & 3,09 \\
\hline Pouteria sp. & 7,50 & 0,69 & 10,00 & 0,85 & 0,23 & 0,57 & 2,11 \\
\hline Protium sp. & 2,50 & 0,23 & 5,00 & 0,42 & 0,04 & 0,10 & 0,75 \\
\hline Pseudobombax grandiflorum & 5,00 & 0,46 & 10,00 & 0,85 & 1,08 & 2,69 & 4,00 \\
\hline Psidium cattleianum & 10,00 & 0,92 & 10,00 & 0,85 & 0,25 & 0,62 & 2,39 \\
\hline Garcinia gardneriana & 5,00 & 0,46 & 10,00 & 0,85 & 0,07 & 0,17 & 1,48 \\
\hline Sapium glandulatum & 2,50 & 0,23 & 5,00 & 0,42 & 0,07 & 0,17 & 0,82 \\
\hline
\end{tabular}




\begin{tabular}{|c|c|c|c|c|c|c|c|}
\hline \multicolumn{8}{|l|}{ Conclusão } \\
\hline \multirow[b]{2}{*}{ ESPÉCIES } & \multicolumn{2}{|c|}{ DENSIDADE } & \multicolumn{2}{|c|}{ FREQÜÊNCIA } & \multicolumn{2}{|c|}{ DOMINÂNCIA } & \multirow[b]{2}{*}{ VI } \\
\hline & $\begin{array}{c}\text { Abs. } \\
\left(\mathrm{N}^{\mathrm{o}} / \mathrm{ha}\right)\end{array}$ & $\begin{array}{l}\text { Rel. } \\
(\%)\end{array}$ & $\begin{array}{c}\text { Abs. } \\
(\%)\end{array}$ & $\begin{array}{l}\text { Rel. } \\
(\%)\end{array}$ & $\begin{array}{c}\text { Abs. } \\
\left(\mathrm{m}^{2} / \mathrm{ha}\right)\end{array}$ & $\begin{array}{l}\text { Rel. } \\
(\%)\end{array}$ & \\
\hline Didymopax angustissimum & 5,00 & 0,46 & 10,00 & 0,85 & 0,04 & 0,10 & 1,41 \\
\hline Didymopax morototoni & 5,00 & 0,46 & 10,00 & 0,85 & 0,09 & 0,21 & 1,52 \\
\hline Senna multijuga & 2,50 & 0,23 & 5,00 & 0,42 & 0,04 & 0,09 & 0,74 \\
\hline Sloanea guianensis & 10,00 & 0,92 & 15,00 & 1,27 & 0,42 & 1,05 & 3,24 \\
\hline Solanum sp. & 2,50 & 0,23 & 5,00 & 0,42 & 0,57 & 1,42 & 2,07 \\
\hline Syagrus romanzoffiana & 95,00 & 8,76 & 60,00 & 5,08 & 3,15 & 7,86 & 21,70 \\
\hline Symplocos uniflora & 2,50 & 0,23 & 5,00 & 0,42 & 0,02 & 0,05 & 0,70 \\
\hline Tabebuia cassinoides & 100,00 & 9,22 & 45,00 & 3,81 & 2,58 & 6,44 & 19,47 \\
\hline Tabebuia umbellata & 5,00 & 0,46 & 5,00 & 0,42 & 0,39 & 0,97 & 1,85 \\
\hline Tapirira guianensis & 40,00 & 3,69 & 55,00 & 4,66 & 2,60 & 6,50 & 14,85 \\
\hline Tibouchina multiceps & 17,50 & 1,61 & 10,00 & 0,85 & 0,24 & 0,60 & 3,06 \\
\hline Trichipteris atrovirens & 42,50 & 3,92 & 30,00 & 2,54 & 0,50 & 1,25 & 7,71 \\
\hline Lauraceae 1 & 2,50 & 0,23 & 5,00 & 0,42 & 0,02 & 0,06 & 0,71 \\
\hline Lauraceae 2 & 5,00 & 0,46 & 5,00 & 0,42 & 0,17 & 0,42 & 1,30 \\
\hline Myrtaceae 1 & 25,00 & 2,30 & 15,00 & 1,27 & 1,33 & 3,32 & 6,89 \\
\hline Myrtaceae 2 & 7,50 & 0,69 & 10,00 & 0,85 & 0,08 & 0,21 & 1,75 \\
\hline N.I. 1 & 2,50 & 0,23 & 5,00 & 0,42 & 0,03 & 0,07 & 0,72 \\
\hline N.I. 3 & 2,50 & 0,23 & 5,00 & 0,42 & 0,12 & 0,30 & 0,95 \\
\hline TOTAL & 1085,00 & 100,00 & 1180,00 & 100,00 & 40,06 & 100,00 & 300,00 \\
\hline
\end{tabular}

(Abreviaturas: Abs. $=$ absoluta Rel. $=$ relativa e VI $=$ valor de importância)

Quanto a sinúsia dos arbustos e das ervas, em alguns locais espécies de Bromeliaceae formam densos tapetes, permeadas de Poaceae (Olyra). São muito comuns também Marantaceae (caetês), Rubiaceae, Acanthaceae, Piperaceae e Zingiberaceae, além de briófitas e pteridófitas e indivíduos em regeneração pertencentes a espécies arbóreas encontradas nos demais estratos. As epífitas são encontradas em maior abundância do que nos demais ambientes estudados. Bactris lindmaniana (Arecaceae) também é muito comum no sub-bosque. Exemplares jovens de Euterpe edulis são observados em abundância, não havendo correspondência numérica de adultos, supostamente, pela ação extrativista predatória ou pela influência limitativa do próprio solo.

Nesse local, os valores médios de densidade total e área basal foram de 1.085 indivíduos por hectare e $40 \mathrm{~m}^{2} / \mathrm{ha}$, respectivamente, esses somente inferiores àqueles obtidos para o caxetal AlexandraMatinhos (49 $\left.\mathrm{m}^{2} / \mathrm{ha}\right)$. Em termos de dominância, Calophyllum brasiliense mostrou os valores mais elevados $\left(9,91 \mathrm{~m}^{2} / \mathrm{ha}\right)$, perfazendo $23 \%$ da área basal total, seguido por Syagrus romanzoffiana $\left(3,15 \mathrm{~m}^{2} / \mathrm{ha}\right)$, Tapirira guianensis $\left(2,60 \mathrm{~m}^{2} / \mathrm{ha}\right)$ e Tabebuia cassinoides $\left(2,58 \mathrm{~m}^{2} / \mathrm{ha}\right)$.
Depreende-se dessas informações que, em função dos valores de importância obtidos, as espécies que imprimem a fisionomia a essa formação são Calophyllum brasiliense $(37,33)$, Syagrus romanzoffiana (20,27), Tabebuia cassinoides $(18,19)$, Tapirira guianensis $(13,85)$, Pera glabrata (11,65) e Alchornea triplinervia $(10,65)$.

\section{Índices de diversidade, de espécies raras e de similaridade}

Com base no complemento do índice de Simpson, os sete caxetais estudados foram ordenados seqüencialmente quanto à diversidade (Tabela 9). Passa-Sete apresentou menor diversidade, com $85 \%$ dos indivíduos pertencentes à espécie Tabebuia. cassinoides, seguido de Batuva (68\%), Cabaraquara (61\%), Atami (53\%), Guaratuba 1 (55\%), AlexandraMatinhos (48\%) e, finalmente, Guaratuba 2 (9\%). Nesse último caso, o número de espécies registrado foi o maior de todos e Tabebuia cassinoides dividiu, em estratos distintos, sua hegemonia com Callophyllum brasiliense, que a supera em área basal. A sequiência definida, por haver sempre uma supremacia de Tabebuia cassinoides, em maior ou menor grau, foi condizente com os resultados da caracterização estrutural. 
Tabela 9: Valores de complemento do índice de Simpson (C.I.S) e Índice de Espécies Raras (I.E.R.) para os caxetais estudados.

Table 9: $\quad$ Simpson Diversity Index (CIS), Modified Simpson Index (ISM) and Rare Species Index (IER) for the sites studied.

\begin{tabular}{|l|c|c|}
\hline CAXETAIS & C.I.S & I.E.R. \\
\hline PST - Passa-Sete & 0,27 & 23,08 \\
BAT - Batuva & 0,51 & 15,38 \\
CAB - Cabaraquara & 0,61 & 29,63 \\
ATA - Atami & 0,69 & 26,67 \\
GT1 - Guaratuba 1 & 0,70 & 38,46 \\
ALE - Alexandra-Matinhos & 0,75 & 27,78 \\
GT2 - Guaratuba 2 & 0,96 & 26,92 \\
\hline Desvio Padrão & 0,21420 & 6,94258 \\
\hline C.V. (\%) & 33,3940 & 25,861 \\
\hline
\end{tabular}

Já o índice de espécies raras representa a percentagem do número de espécies amostradas com apenas um indivíduo em relação ao número total de espécies amostradas e fornece uma indicação da suficiência e representatividade da amostragem. Se tal proporção for alta, há uma tendência de que espécies deixem de ser amostradas em função de sua raridade de ocorrência (McIntosh, 1985). Para as unidades estudadas, o índice variou de 15 até $38 \%$, com predominância de valores inferiores a $30 \%$. Tais valores, embora altos, encontram-se dentro de uma faixa tolerável de 25,0 e $39,5 \%$, exemplificada por Cavassan et al. (1984) em vários trabalhos, o que dá confiabilidade ao processo amostral, mesmo tendo-se presente o fato de as comunidades terem sido amostradas com intensidades distintas.
Os índices de similaridade calculados entre os caxetais estudados (Tabela 10) expressam uma grande semelhança florística entre os caxetais, tendo em vista que os valores obtidos quase sempre superam 25, valor acima do qual já se consideram semelhantes às unidades confrontadas (Mueller-Dombois e Ellenberg, 1974). A maior semelhança florística ocorre entre os caxetais Alexandra-Matinhos e Atami, seguidos de Alexandra-Matinhos e Cabaraquara, e Atami e Cabaraquara, entre outros. Por outro lado, não há similaridade florística de Guaratuba 2 com nenhum dos demais caxetais, assim como de Atami e Guaratuba 1 entre si e em relação ao Batuva. Com base nesses dados, foi obtido um coeficiente de variação muito elevado, de 41,6 $\%$.

Tabela 10: Índices de similaridade de Jaccard para os caxetais estudados.

Table 10: Jaccard similarity indexes for the sites studied.

\begin{tabular}{|c|c|c|c|c|c|c|}
\hline CAXETAIS & BAT & CAB & ALE & ATA & GT1 & GT2 \\
\hline PST & 30.0 & 29.0 & 29.3 & 27.3 & 30.0 & 9.63 \\
BAT & & 25.0 & 32.4 & 16.7 & 11.43 & 7.05 \\
CAB & & & 40.0 & 40.0 & 29.26 & 16.66 \\
ALE & & & & 47.7 & 26.53 & 21.27 \\
ATA & & & & & 20.83 & 13.80 \\
GT1 & & & & & & 22.35 \\
\hline
\end{tabular}

\section{CONCLUSÕES}

A utilização dos caxetais, na forma de explorações cíclicas, altera significativamente suas características florísticas e fitossociológicas, fato que dificulta uma confrontação segura dos diferentes locais abordados neste estudo. Mesmo assim, uma breve comparação de alguns de seus aspectos básicos, como a diversidade, a densidade, a dominância arbórea, a expressividade da caxeta na comunidade, o porte e o número de estratos, permite ordená-los na seqüência como foram apresentados, ou seja, do menor para o maior grau de desenvolvimento, conforme representação genérica no esquema sucessional apresentado na Figura 10. 


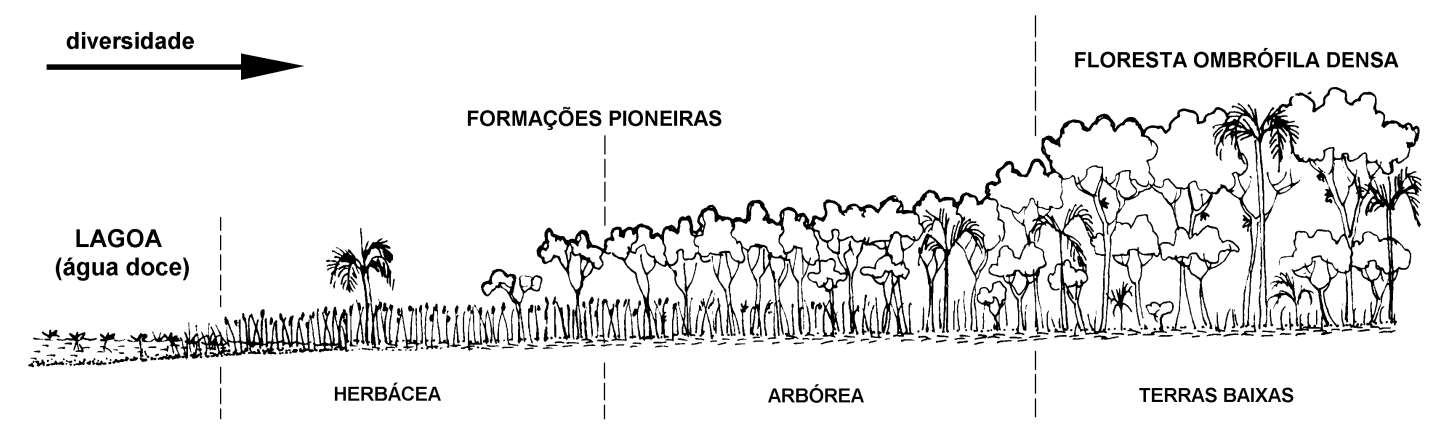

Figura 10: Esquema de desenvolvimento sucessional em que os caxetais constituem estágios da Floresta Ombrófila Densa das Terras Baixas.

Figure 10: Successional development scheme in which the caxeta sites are pioneer stages of the Lowland Dense Ombrophilous Forest.

A expressão Formações Pioneiras, sugerida pelo IBGE (1992), é usada para denominar o tipo de cobertura vegetal formado por espécies colonizadoras de ambientes atuais, áreas subtraídas naturalmente de outros ecossistemas ou surgidas em função da atuação recente dos agentes morfodinâmicos e pedogenéticos (Leite, 1994). As espécies ditas pioneiras desempenham importante papel ambiental, alterando as condições microambientais e pedológicas, o que permite a instalação subseqüente de espécies mais exigentes ou menos adaptadas às condições de instabilidade ambiental e de alta intensidade luminosa. Formações Pioneiras são, pois, formações vegetais em fase inicial de sucessão, com ecossistemas dependentes de fatores ecológicos instáveis.

As Formações Pioneiras podem ser, em geral, classificadas quanto à estrutura e à fisionomia, em herbáceas, arbustivas e arbóreas. No caso dos caxetais, a instalação da comunidade começa, por exemplo, com exclusividade de Typha domingensis ou de Fuirena umbellata, espécies que funcionam como vegetação herbácea colonizadora de áreas de grande instabilidade física.

Formada essa cobertura inicial, está preparado o ambiente para a entrada de vegetação um pouco mais exigente, no caso, arbórea, representada por Tabebuia cassinoides. À medida que se configura um estrato contínuo e homogêneo de caxeta, que produz sombreamento para a vegetação herbácea original e, simultaneamente, modifica as condições do meio físico, o ambiente se torna desfavorável para as espécies pioneiras, essencialmente heliófilas, que gradualmente são eliminadas da formação. Dessa forma se abre, por conseqüência, espaço para outras espécies mais adaptadas às condições do momento, aumentando a diversidade do sub-bosque com uma série de espécies companheiras da caxeta.

O crescimento desses novos indivíduos, de espécies diversas, muda lenta e gradativamente a fisionomia inicial de homogeneidade absoluta dos caxetais. Além da mudança na diversidade, devida tanto ao aumento do número de espécies como à maior equanimidade na distribuição de indivíduos por espécie, ocorrem mudanças estruturais que serão tanto mais significativas quanto maior o número de estratos e a altura do dossel. A grande mudança se dá quando Calophyllum brasiliense ultrapassa Tabebuia cassinoides em altura e vai formar, junto a outras espécies de grande porte como Ficus spp., Pseudobombax grandiflorum, Tapirira guianensis e Syagrus romanzoffiana, o estrato superior. Tabebuia cassinoides passa então a ocupar um segundo plano no estrato médio, ponto a partir do qual, em função da mais baixa intensidade luminosa que recebe, sai gradativamente da formação.

Essa seqüência sucessional pode ser observada na ordenação sugerida para descrever os diferentes ambientes estudados que, apesar de fundamentada na diversidade, coincide com o declínio de Tabebuia 
cassinoides e com o aumento, ainda que lento, de Calophyllum brasiliense (Figura 11), embora Guaratuba 1 possa se constituir em uma exceção nesse sentido. Apesar da menor densidade de Calophyllum brasiliense e da maior densidade de Tabebuia cassinoides, o índice de diversidade dessa comunidade é praticamente idêntico ao calculado para Atami, onde a ocorrência de Calophyllum brasiliense é mais expressiva.

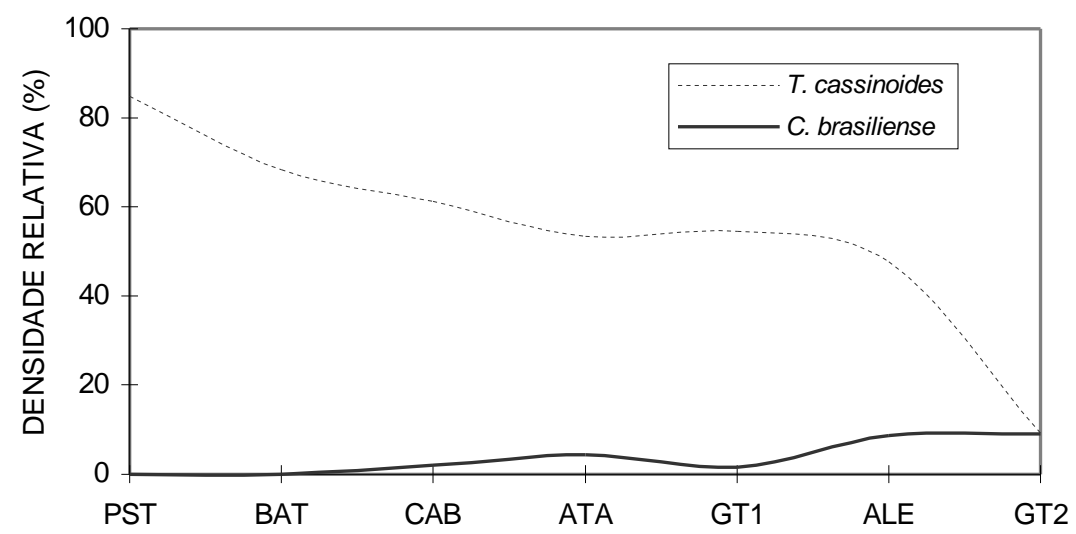

Figura 11: Densidades de Tabebuia cassinoides e de Calophyllum brasiliense nos diferentes caxetais estudados. Figure 11: Tabebuia cassinoides and Calophyllum brasiliense densities in the different sites studied.

O ponto a partir do qual a caxeta deixa de predominar no dossel, destacando-se fisionômica e estruturalmente outras espécies, em especial Calophyllum brasiliense, Ficus sp. e Tapirira guianensis, marca o final da etapa sucessional das Formações Pioneiras e o início da Floresta Ombrófila Densa das Terras Baixas. O conceito de floresta implica necessariamente a ocupação de uma área por indivíduos arbóreos de várias espécies (alta diversidade) em diferentes estratos (Hertel, 1969), enquanto que as Formações Pioneiras, na fase de ocupação arbórea, caracterizam-se por diversidade baixa, ou seja, predomínio de uma ou de poucas espécies, quase sempre ocupando um único estrato (Leite e Klein, 1990; Leite, 1994). Ambas as expressões só são válidas se o processo de estabelecimento de espécies se dá de forma natural.

Segundo esta conceituação, os caxetais Passa-Sete e Batuva são os que melhor se enquadram na denominação de Formações Pioneiras de Influência Fluvial, em função da baixa diversidade detectada e dos elevados percentuais de densidade obtidos para a caxeta (na ordem, 84,7 e 68,2\%) dentro das respectivas comunidades arbóreas.

Os caxetais Cabaraquara, Atami e Guaratuba 1 podem ainda ser enquadrados como tal, em especial dado que Tabebuia cassinoides ainda é dominante no estrato superior, porém já evidencia franca transição para a Floresta Ombrófila Densa das Terras Baixas com o início da formação de um terceiro estrato arbóreo, onde serão dominantes outras espécies.

Os caxetais Alexandra-Matinhos e Guaratuba 2 enquadram-se na categoria de Floresta Ombrófila Densa das Terras Baixas, em especial o segundo, em função de sua elevada riqueza (78 espécies), diversidade (CIS $=0,96$ ), da menor representatividade de Tabebuia cassinoides na comunidade $(8,9 \%)$ e da altura do dossel, entre 20 e 24 metros.

Por fim, as intenções de manejo para aproveitamento desse recurso natural devem priorizar as Formações Pioneiras de Influência Fluvial, onde a caxeta é dominante, de forma a reduzir os impactos sobre um conjunto maior de espécies e sobre ambientes de maior complexidade. A definição estrita de "caxetal" deveria ficar, portanto, reduzida aos estágios sucessionais iniciais em que a caxeta ocupa o estrato arbóreo superior e apresenta densidade relativa acima de $50 \%$.

\section{AGRADECIMENTOS}

Os autores agradecem aos pedólogos Gustavo Ribas Curcio e Marcos Fernando Gluck Rachwal, pesquisadores do Centro Nacional de Pesquisa em Florestas da 
EMBRAPA, pela importante colaboração em várias fases desse trabalho.

\section{BIBLIOGRAFIA CITADA}

ANDRADE, M. A. B. de. Contribuição ao conhecimento da ecologia das plantas das dunas do litoral do estado de São Paulo. Boletim Fac. Fil. Ci. e Letras, n. 305, Botânica, n. 22, São Paulo: USP, p. 3-170, 1967.

ANGulo, R. J. Geologia da Planície Costeira do estado do Paraná. São Paulo, 1992. 334f. Tese (Doutorado em Geologia Sedimentar). Instituto de Geociências, Universidade Estadual de São Paulo.

ATHAYDE, S. F. Composição florística e estrutura fitossociológica em quatro estágios sucessionais de uma Floresta Ombrófila Densa Submontana, como subsídio ao manejo ambiental Guaraqueçaba/PR. Curitiba, 1997. 163f. Dissertação (Mestrado em Botânica). Setor de Ciências Biológicas, Universidade Federal do Paraná.

CAVASSAN, O.; CESAR, O.; MARTINS, F. R. Fitossociologia da vegetação arbórea da Reserva Estadual de Bauru, estado de São Paulo. Revta. brasil. Bot., São Paulo, v. 7, n. 2 p. 91-106, 1984.

GUAPYASSÚ, M. S. Caracterização fitossociológica de três fases sucessionais de uma Floresta Ombrófila Densa Submontana Morretes - Paraná. Curitiba, 1994. 150 pf. Dissertação (Mestrado em Engenharia Florestal). Setor de Ciências Agrárias, Universidade Federal do Paraná.

HERTEL, R. J. G. Aspectos interessantes da vegetação do Paraná. In: História do Paraná. v. 2, Curitiba: Gráfica Editora Paraná Cultural Ltda, p. 131-241, 1969.

IAPAR. Cartas climáticas básicas do estado do Paraná. Londrina: IAPAR, 45 p. 1994.

IBGE. Manual técnico da vegetação brasileira. Manuais técnicos em geociências, n. 1. Rio de Janeiro: IBGE, 91p. 1992.

KUNIYOSHI, Y.S. Aspectos morfoanatômicos do caule, raiz e folha de
Tabebuia cassinoides (Lam.) DC. (Bignoniaceae) em diferentes estágios sucessionais no estado do Paraná. Curitiba, 1993. 131f. Tese (Doutorado em Engenharia Florestal). Setor de Ciências Agrárias, Universidade Federal do Paraná.

LEITE, P. F. As diferentes unidades fitoecológicas da Região Sul do Brasil. Proposta de classificação. Curitiba, 1994. 160 f. Dissertação (Mestrado em Engenharia Florestal). Setor de Ciências Agrárias, Universidade Federal do Paraná.

LEITE, P. F.; KLEIN, R. M. Vegetação. In: IBGE - Geografia do Brasil: região Sul. v. 2. Rio de Janeiro: IBGE, p.113-150, 1990.

LÓLIS, S. F. Análise fitossociológica de um estágio seral de Floresta Ombrófila Densa das Terras Baixas, Reserva de Volta Velha Itapoá - SC. Curitiba, 1996. 99f. Dissertação (Mestrado em Botânica). Setor de Ciências Biológicas, Universidade Federal do Paraná.

MAACK, R. Geografia física do estado do Paraná. Curitiba: José Olympio, 450p. 1981.

MAGURRAN, A.E. Diversidad ecológica y su medición. Barcelona: Vedrá, 200p. 1989.

McINTOCH, R. P. The background of ecology: concept and theory. New York: Cambridge University Press, 383p. 1985.

MENEZES-SILVA, S. Composição florística e fitossociologia de um trecho de floresta de restinga na Ilha do Mel, Município de Parananguá, PR. Campinas, 1990.146f. Dissertação (Mestrado em Biologia Vegetal), Instituto de Biologia, Universidade Estadual de Campinas.

MENEZES-SILVA, S. As formações vegetais da planície litorânea da Ilha do Mel, Paraná, Brasil: Composição florística e principais características estruturais. Campinas, 1998. 262f. Tese (Doutorado em Ciências Biológicas), Instituto de Biologia, Universidade Estadual de Campinas.

MUELLER-DOMBOIS, D.; ELLENBERG, $\mathrm{H}$. Aims and methods of vegetation ecology. New York: John Wiley \& Sons, 547p. 1974. 
RACHWALL, M. F. G.; CURCIO, G. R. Atributos pedológicos e ocorrência de caixeta no litoral paranaense - Brasil. Sciencia Forestalis, n. 59, p. 153-163, jun. 2001.

RODERJAN, C. V.; KUNIYOSHI, Y. S.; GALVÃO, F.; HATSCHBACH， G. G.; KIRCHNER, F. F. Levantamento da vegetação da Área de Proteção Ambiental de Guaratuba - APA de Guaratuba. Curitiba: Universidade Federal do Paraná, 78p.1997.

SHEPHERD, G. J. FITOPAC: Manual do usuário. Campinas: Universidade Estadual de Campinas, 32p. 1994.

ZILLER. S. R. Análise fitossociológica de caxetais. Curitiba, 1992. 101 f. Dissertação (Mestrado em Engenharia Florestal). Setor de Ciências Agrárias, Universidade Federal do Paraná. 